\title{
In Situ Synthesis of Phenoxazine Dyes in Water: A Cutting-Edge Strategy to "Turn-On" Fluorogenic and Chromogenic Detection of Nitric Oxide
}

\author{
Sébastien Jenni, ${ }^{\#, \&\left[{ }^{[a]}\right.}$ Kévin Renault,, ${ }^{\#, \&[a]}$ Garance Dejouy, ${ }^{[a]}$ Sylvain Debieu ${ }^{[a]}$ Myriam Laly, ${ }^{[a]}$ and \\ Anthony Romieu*[a]
}

[a] Dr. S. Jenni, Dr. K. Renault, Dr. G. Dejouy, Dr. S. Debieu, Dr. M. Laly, Prof. Dr. A. Romieu Institut de Chimie Moléculaire de l'Université de Bourgogne, UMR 6302, CNRS

Univ. Bourgogne Franche-Comté

9, Avenue Alain Savary

21000 Dijon (France)

E-mail: sebastien.jenni@unige.ch, kevin.renault@unamur.be or anthony.romieu@u-bourgogne.fr

\#These authors contributed equally to this work.

§Present addresses: Laboratory of Pharmaceutical Technology, School of Pharmaceutical Sciences, ISPSO, University of Geneva, Rue Michel-Servet 1, CH1211 Genève, Switzerland (SJ).

Département de Chimie, Laboratoire de Chimie Bio-Organique, University of Namur (FUNDP), Rue de Bruxelles 61, Namur B-5000, Belgium $(\mathrm{KR})$

Abstract: The synthesis of phenoxazine dyes was revisited in order to access these fluorescent N,O-heterocycles under mild conditions. The combined sequential use of nitrosonium tetrafluoroborate $\left(\mathrm{NOBF}_{4}\right)$ and triphenylphosphine enables the facile conversion of bis(3dimethylaminophenyl) ether into the methyl analog of popular laser dye oxazine 1 . The ability of nitrosonium cation ( $\left.\mathrm{NO}^{+}\right)$to initiate the domino reaction resulting in $\pi$-conjugated phenoxazine molecules under neutral conditions, then led us to explore the feasibility of expanding it in aqueous media. Thus, we explored the use of reactive signaling molecule nitric oxide (NO) as a biological trigger of phenoxazine synthesis in water. The implementation of a robust analytical methodology based on fluorescence assays and HPLCfluorescence/-MS analyses, have enabled us to demonstrate the viability of this novel fluorogenic reaction-based process to selectively yield an intense "OFF-ON" response in the near-infrared (NIR-I) spectral region. This study is an important step towards the popularization of the concept of "covalent-assembly" in the fields of optical sensing, bioimaging and molecular theranostics.

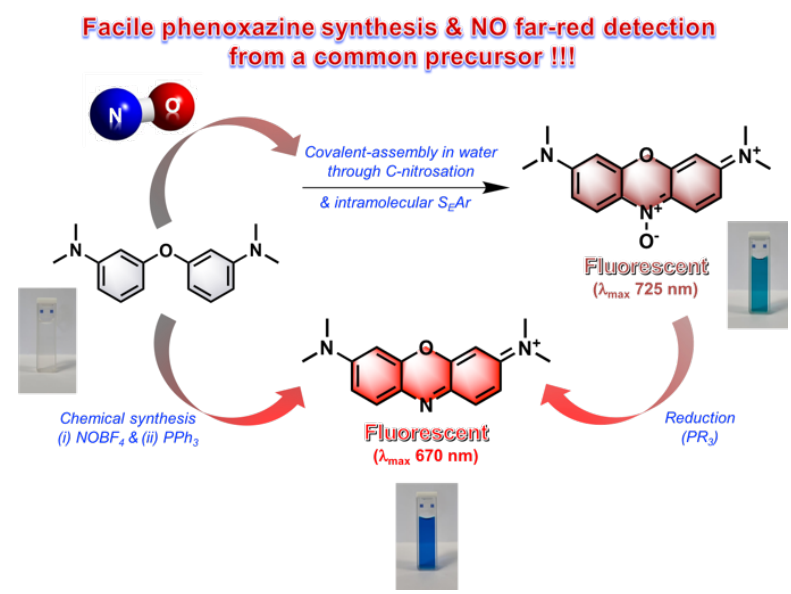

Keywords: covalent-assembly $\bullet$ domino reactions $\bullet$ fluorescent probe $\bullet$ nitric oxide $\bullet$ phenoxazine dyes

\section{Introduction}

Phenoxazine dyes, formally defined as anthracene analogs in which the middle ring is replaced by a morpholine unit, are an important class of heterocycles, mainly explored both for their biological activities and their ability as high-performance biological staining agents. ${ }^{[1]}$ Among the myriad of synthetic compounds belonging to the phenoxazine family, those decorated with a pair of electron-donating and -withdrawing groups as substituents (i.e., push-pull substituents) and/or structurally fused with a further benzene ring (e.g., "angular" or "linear" benzophenoxazines $)^{[2]}$ for elongation of their $\pi$-conjugated system, often exhibit good fluorescence within the orange-red spectral range or beyond $650 \mathrm{~nm}$ in the first near-infrared (NIR-I) region. ${ }^{[3]}$ This emissive capability is characterized by the following features: high quantum yields mainly in non-polar solvents, large Stokes' shifts and a high sensitivity to the surrounding environment (polarity, viscosity, ...) leading to marked solvatochromism. The most popular phenoxazine-based fluorophores are Nile Red, Nile Blue, Cresyl Violet and its nonmethylated analog Oxazine 9 (Figure 1). The latter ones and close structural analogs are used for the most demanding fluorescencebased biosensing/bioimaging applications. ${ }^{[4]}$ Indeed, they take advantage of their unique ability to be used either as non-covalent labeling agents highly selective for some biological structures/assemblies (e.g., membranes and lipid microdomains ${ }^{[5]}$, amyloid fibrils ${ }^{[6]}, D^{2} A^{[7]}$ and related unusual nucleic acids structures such as G-quadruplexes ${ }^{[8]}$ ) or as reactive fluorescent labels if a bioconjugatable handle is available within their core structure. Furthermore, the presence of a primary aniline moiety or the possible introduction of an additional phenol, both acting as 
effective optically tunable groups, imparts these molecules fluorogenic reactivity, which is of primary importance for designing reaction-based small-molecule fluorescent probes. Thus, the probe design strategy based on protection-deprotection of an amino or hydroxyl group ${ }^{[9]}$ was successfully applied especially to the detection of biologically relevant analytes including enzymatic biomarkers, biomolecules (e.g., biothiols) and gasotransmitters, most often through an intensometric "OFF-ON" response. ${ }^{[10]}$ Interestingly, analyte- or environment-assisted modulation of other photophysical processes such as Förster resonance energy transfer (FRET) or through-bond energy transfer (TBET) has also been regarded for biosensing/biomaging operations based on the use of "smart" phenoxazine reporters. ${ }^{[11]}$ Other benefit of these probe developments is related to the major advances made in the chemistry of parent fluorophores aimed at improving their spectral features, bioconjugation ability, water solubility and cell permeation or amphiphilic character and targeting properties. Major contributions in this field, notably from the Belov-Hel[ [12], Burgess $^{[13]}$, Gonçalves ${ }^{[14]}$, Klymchenko ${ }^{[5]}$ and Milller ${ }^{[15]}$ groups are worthy of note.

Inspired by the conventional synthetic methods typically used for preparing (benzo)phenoxazine derivatives and based on an acidcatalyzed condensation reaction between a nitroso intermediate and an electron-rich aromatic compound (typically, a phenylogous amine or a phenol) as the key step, the Yang group has explored a new probe design principle, namely the "covalent-assembly" approach ${ }^{[16]}$, for detecting ROS/RNS through in situ formation of fluorescent phenoxazine dyes or related analogs (i.e., coumarinresorufin fused compounds) ${ }^{[17]}$ (Figure 2). The positive attributes of this novel class of activatable fluorescent probes relating to their ability to dramatically improve signal-to-noise ratio $(\mathrm{S} / \mathrm{N})$ responses, and hence to provide optimal detection sensitivity, led us to devise a novel water-compatible cascade reaction triggered by an enzyme (i.e., penicillin $G$ acylase (PGA) used as model protease) and potentially producing fluorescent 9 -amino-5Hbenzo[a]phenoxazin-5-one (Figure 2). Indeed, this is a vital step towards applying the "covalent-assembly" principle to in vivo medical diagnostics through the use of "smart" NIR-I fluorescent imaging agents activated by disease-associated enzymes or other reactive biomarkers. ${ }^{[18]}$ However, in vitro enzymatic assays conducted with PGA-sensitive dual-reactable probe 1 and based on fluorescence measurements and HPLC-MS analyses have not enabled us to demonstrate the assumed reaction-based sensing mechanism. Indeed, PGA failed to hydrolyze the second triggering unit phenylacetamide and two distinct compounds 2 and 3, that differ structurally from the expected fluorophore, have been identified. Possible structures based on an unusual fused four-ring heterocyclic system named 11a,12-dihydro-11Hbenzo[b]phenoxazine-6,11(5aH)-dione, have been proposed (Figure 2). To overcome this major bottleneck associated with the application of "covalent-assembly" probe design principle to (benzo)phenoxazine dyes, we brainstormed on a different strategy that takes advantage of water-compatible reactions that have already proven successful in this context, and reported by Yang and Anslyn ${ }^{[19]}$, and our group ${ }^{[20]}$ : (1) effective nitrosation of anilines or electron-rich aromatic derivatives with dinitrogen trioxide $\left(\mathrm{N}_{2} \mathrm{O}_{3}\right)$, the oxidized surrogate of important biologically produced gasotransmitter nitric oxide (NO), and (2) facile ring closure of mixed biphenyl derivatives or bis-aryl ethers through an intramolecular electrophilic aromatic substitution ( $\left.S_{E} A r\right)$ reaction involving a phenylogous amine. We have therefore hypothesized that $\mathrm{NO}^{+}$or $\mathrm{N}_{2} \mathrm{O}_{3}$ could trigger in situ formation of phenoxazine dyes from readily accessible symmetrical bis-aryl ethers, under aqueous conditions, and through a novel domino process involving aromatic $C$-nitrosation followed by intramolecular nucleophilic addition of the adjacent phenylogous amine. We assume that $\mathrm{N}$-oxide phenoxazine formed may be fluorescent and/or prone to biological reduction ${ }^{[21]}$ to give the targeted far-red emitting phenoxazine dye (Figure 3).

Herein, we report the practical implementation of this unprecedented fluorogenic cascade reaction with the dual aim of expanding the scope of "covalent-assembly" principle to longwavelength fluorophores and establishing a novel and effective sensing scheme for NO. The versatility of this approach was also examined by considering several phenoxazine precursors that differ from each other through the nature of their electron-donating dialkylamino groups or by the presence of a dimethylsilicon moiety instead of the bridging oxygen atom. Indeed, these structural modifications are often applied to different classes of organic-based fluorophores (e.g., phenoxazines ${ }^{[15 b, 22]}$, rhodamines $\left.{ }^{[23],[24]}, \ldots\right)$, to improve and red-shift their spectral properties. In addition to these synthetic aspects, a set of in vitro fluorescence assays and HPLC-fluorescence/-MS analyses was undertaken to study in detail NO-mediated construction of phenoxazine dyes.

\section{Results and Discussion}

As briefly mentioned above, the traditional synthetic method often employed for preparing common angular phenoxazine dyes (i.e., Nile Red and Nile Blue derivatives) is based on an acid-mediated condensation reaction between a nitrosylated aminophenol and an hydroxy- or aminonaphthalene, conducted under harsh conditions (i.e., conc. $\mathrm{HCl}$, polar solvent such as EtOH or DMF heated under reflux or at $80-90{ }^{\circ} \mathrm{C}$ respectively). ${ }^{[3]}$ Our proposed approach distinguished by the implementation of a NO-mediated cyclization process as the key synthetic step, may offer distinct advantages including milder reaction conditions (vide infra) and the use of a structurally simple symmetrical bis-aryl ether as a "covalent-assembly" precursor of phenoxazine. Our initial efforts were then devoted to the synthesis of such aromatic ethers and a hetero-analog in which the bridging oxygen atom is replaced by the dimethylsilicon moiety.

\section{Synthesis of symmetrical bis-aryl ethers and a silicon- containing analog}

The straightforward synthetic route employed for the rapid preparation of bis(3-dimethylaminophenyl) ether $\mathbf{4}$ is based on a copper-catalyzed Ullmann-type C-O cross-coupling reaction between 3-(dimethylamino)phenol and 3-bromo-N,Ndimethylaniline, conducted under conditions historically proposed by the Cornish group ${ }^{[25]}$ and recently optimized by us to readily obtain precursors of pyronin dyes ${ }^{[26]}$ (Scheme 1). The use of a commercially available bromoarene as electrophilic coupling partner instead of its iodo counterpart (whose synthetic accessibility requires formal $\mathrm{N}, \mathrm{N}$-dimethylation of commercial 3iodoaniline) has not given rise to any major problems of reactivity and the desired phenoxazine precursor 4 was obtained with a satisfying but not optimized $75 \%$ yield. For the purpose of possibly improving kinetics of the NO-triggered "covalent-assembly" process and optimizing photophysical properties of in situ formed 
phenoxazine (i.e., red-shifting of absorption/emission maxima and enhancement of fluorescence quantum yield) through a molecular rigidification approach, the synthesis of symmetrical bis-aryl ether 5 bearing two julolidine units was also attempted. Nevertheless, despite several attempts for which the copper source, the ligand, the base and the solvent were varied, this Ullmann coupling product was never detected from RP-HPLC-MS analyses of the reaction mixtures. We also noted the degradation of starting 8-hydroxyjulolidine. We assume a lack of reactivity of 8-bromojulolidine that is electron-enriched compared to 3-bromo$\mathrm{N}, \mathrm{N}$-dimethylaniline, as a result of the greater electron-donating ability of its dialkylamino group than that of dimethylamino moiety. Furthermore, to the best of our knowledge, the iodo counterpart, perhaps more reactive in this context, has never been reported and its synthetic accessibility seems to be not a trivial task.

Since a reliable and effective synthetic route to obtain the silicon analog of bis(3-dimethylaminophenyl) ether (diaryl ether analog 6, recently abbreviated by Deng et al. DAEA-Si) has already been devised and reported in the literature ${ }^{[27]}$, no improvement has been made by us in the practical implementation of lithiumhalogen exchange reaction between 3-bromo-N,Ndimethylaniline and $n$-BuLi, and subsequent silylation with $\mathrm{Me}_{2} \mathrm{SiCl}_{2}$. DAEA-Si 6 was obtained in a pure form after conventional flash-column chromatography over silica gel (yield $39 \%)$.

\section{Mild condition synthesis of phenoxazine dye 8 and its silicon analog 10 through nitrosation in an organic medium}

The bench-stable, commercially available nitrosating agent, nitrosonium tetrafluoroborate $\left(\mathrm{NOBF}_{4}\right)^{[28]}$ has been recently used for the facile synthesis of aromatic azo compounds under mild conditions particularly well-suited for reactions involving highly functionalized tertiary anilines as coupling partners. ${ }^{[29]}$ Surprisingly, to the best of our knowledge, $\mathrm{NOBF}_{4}$ has still not be used as the source of nitrosonium $\left(\mathrm{NO}^{+}\right)$cation in the synthesis of (benzo)phenoxazine dyes. In order to demonstrate that this electrophilic species is able to trigger the phenoxazine dyes synthesis in situ, under neutral mild conditions, bis(3dimethylaminophenyl) ether 4 was reacted with 1 equiv. of $\mathrm{NOBF}_{4}$, in $\mathrm{MeCN}$ at room temperature (Scheme 2). The complete consumption of starting 4 was observed within only 5 min and formation of a deeply blue-green colored compound identified as $\mathrm{N}$-oxide phenoxazine dye $\mathbf{7}$ was observed. Isolation of this unprecedented aminated analog of resazurin (RZ), N-oxide derivative of resorufin (RF) and currently used as indicator of cell viability ${ }^{[30]}$, was achieved by conventional flash-column chromatography over silica gel (isolated yield $25 \%$ ). This modest but not optimized yield can be explained by the presence of nitronium tetrafluoroborate $\left(\mathrm{NO}_{2} \mathrm{BF}_{4}\right)$ in the old batch of $\mathrm{NOBF}_{4}$ used, leading to undesired nitration reactions of 4 . Yield improvement can be achieved using a fresh bottle of NOBF 4 . Deoxygenation of this $\mathrm{N}$-oxide was readily achieved using a slight excess of triphenylphosphine (1.2 equiv.) in $\mathrm{MeCN}$ at room temperature ${ }^{[31]}$, to give 3,7 -bis(dimethylamino)phenoxazin-5-ium dye 8. Purification by semi-preparative RP-HPLC has enabled its isolation in a pure form and as TFA salt (isolated yield: $65 \%$ ). All spectroscopic data, especially NMR and mass spectrometry data, were in agreement with the two structures assigned. The quantitative determination of fluorophore counter-ion (1x tetrafluoroborate $\mathrm{BF}_{4}^{-}$and $2.37 x$ trifluoroacetate $\mathrm{CF}_{3} \mathrm{CO}_{2}^{-}$for 7 and 8 respectively) was achieved by ionic chromatography. The purity of both compound (determined through RP-HPLC analyses at different wavelength channels) was found to be equal to or above $97 \%$, and thus being suitable for the reliable study of their photophysical properties. From a mechanistic point of view, we assume that $\mathrm{NO}^{+}$ion readily reacts with one of the two identical electron-rich benzene unit of $\mathbf{4}$, through a conventional electrophilic aromatic substitution ( $\left.S_{E} A r\right)$ reaction (Figure 3 ). The regioselectivity of this step was governed by the strong electrondonating ability of dimethylamino group and functionalization only at the $\mathrm{C}-6$ position (i.e., para position relative to $-\mathrm{NMe}_{2}$ group) was observed. The nitroso intermediate may have to undergo intramolecular nucleophilic attack of the adjacent phenylogous dimethylamino unit, to give after abstraction of the ring junction proton, $\mathrm{N}$-oxide phenoxazine dye 7.

Backed by this first success in the direct and facile synthesis of long-wavelength fluorophores from a structurally simple bis-aryl ether, we next examined the preparation of red-shifted silicon analog 10 from DAEA-Si $\mathbf{6}^{[27]}$. However, the reaction between this dimethyldiarylsilane and $\mathrm{NOBF}_{4}$ conducted under the same nonacidic conditions, did not provide the desired $\mathrm{N}$-oxide Si-oxazine dye (azasiline dye) but a mixture of nitroso and nitro derivatives of starting compound. The tetrahedral geometry around the silicon atom of $\mathbf{6}$ and the longer C-Si bond length are unlikely to favor the intramolecular bridging reaction between the nitrosoaryl and phenylogous amine moieties in contrast to what was occurred with bis-aryl ether $4^{[15 b]}$

\section{Photophysical properties of phenoxazine dye 8 and its $\mathrm{N}$ - oxide derivative 7}

The electronic absorption and fluorescence spectra of phenoxazine dye 8 and its $\mathrm{N}$-oxide parent compound 7 were recorded in DMSO (as a representative polar organic solvent), and in several different aqueous media (i.e., ultrapure water, $0.1 \%$ aq. formic acid $\mathrm{pH} 2.1,50 \mathrm{mM}$ HEPES buffer $\mathrm{pH} 7.4$ ) used in the in vitro fluorescence assays and HPLC-fluorescence/-MS analyses in place to demonstrate fluorogenic detection of NO via the "covalent-assembly" principle (see next section). Table 1 summarizes the corresponding spectral features and overlay of the normalized absorption/excitation/emission spectra in DMSO and water are displayed in Figure 4. Not surprisingly, whatever the polar medium used, and by analogy with popular laser dye oxazine 1 (also known as oxazine $725,0 x-1)^{[32]}, 8$ displays a broad and intense absorption band in the visible region of the spectrum with a maximum close to $650 \mathrm{~nm}$, and assigned to the $0-0$ band of the $S_{0}-S_{1}$ transition (electronic transition of $\pi-\pi^{*}$ type). The short-wavelength shoulder at $\lambda \approx 600 \mathrm{~nm}$ has a vibronic origin (i.e., the sum of the vibronic subbands of the $S_{0}-S_{1}$ transition). The alternative hypothesis to explain the shape of this absorption band, linked to the formation of non-emissive aggregates (i.e., H-type homodimers), is absolutely excluded. Indeed, a perfect matching between the absorption and excitation spectra of 8 recorded in DMSO or aq. buffers, for concentrations within the range $5-20 \mu \mathrm{M}$, is observed (Figure 4). Excitation at $600 \mathrm{~nm}$ leads to an intense far-red emission band centered at 666-676 nm. Values of fluorescence quantum yield in polar protic media (determined using Nile Blue in EtOH as standard, $\Phi_{\mathrm{F}}=27 \%$, see Table 1) are comparable to that of $\mathbf{O x}-1$ in $\mathrm{EtOH}$, and as expected, a significant increase was obtained in the higher-viscosity solvent DMSO. 


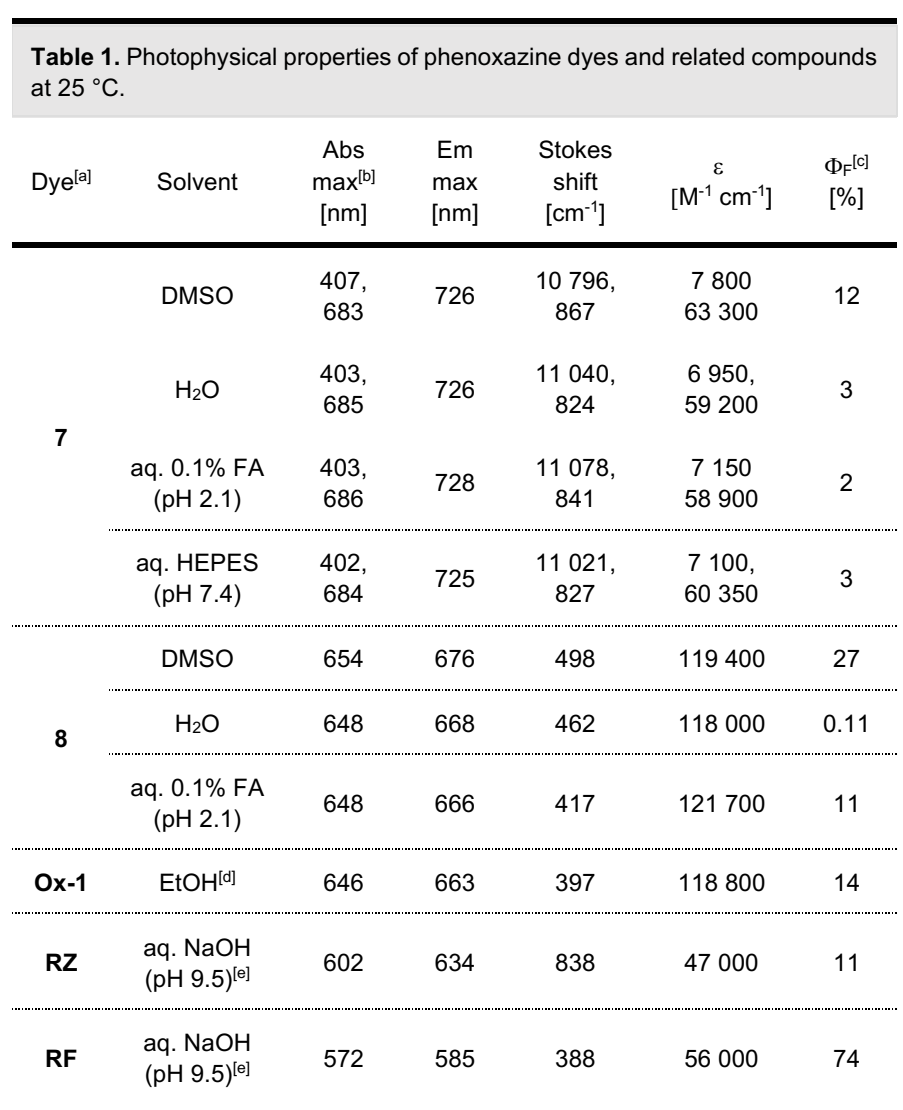

[a] Stock solutions $(1.0 \mathrm{mg} / \mathrm{mL})$ of fluorophores prepared in DMSO. [b] Only 00 band of the $S_{0}-S_{1}$ transition of phenoxazine unit is reported only for $\mathbf{8}$. [c] Determined using an aza-BODIPY dye $\left(\Phi_{\mathrm{F}}=36 \%\right.$ in $\mathrm{CHCl}_{3}$, Ex at $\left.630 \mathrm{~nm}\right)$ or Nile Blue $\left(\Phi_{\mathrm{F}}=27 \%\right.$ in EtOH, Ex at $\left.600 \mathrm{~nm}\right)$ as a standard ${ }^{[33]}$. [d] Values determined and reported by Rurack and Spieles ${ }^{[32]}$. [e] Values determined and reported by Bueno et al. ${ }^{[34]}$

By analogy with its phenolic analog $\mathbf{R} \mathbf{Z}^{[34]}$, the UV-visible absorption spectra of $\mathrm{N}$-oxide derivative 7 consist of an intense band at ca. $685 \mathrm{~nm}$ and a weak band at ca. $400 \mathrm{~nm}$ respectively assigned to $\pi-\pi^{*}$ transition of the phenoxazine ring system and n$\pi^{*}$ transition of $\mathrm{N}$-oxide moiety. Interestingly, the large change in absorption features between this compound and its reduced form 8 enables their facile naked-eye distinction, especially in aq. solution (blue-green and cyanine 5 blue color respectively, see Figure S1). Furthermore, a marked bathochromic shift (ca. +50 $\mathrm{nm}$ ) in emission maximum and a decrease of fluorescence quantum yield (determined using an aza-BODIPY dye in $\mathrm{CHCl}_{3}$ as standard, $\Phi_{\mathrm{F}}=36 \%$, see Table 1) are also obtained whatever the polar solvent used. However, it is interesting to note that this far-red fluorescence decline is much less important than the one reported for the pair RF-RZ (see Table 1). Gratifyingly, this study has enabled us to identify a novel NIR-I fluorescent organic dye with valuable features: compact structure and small molecular weight, low hydrophobicity and resistance to aggregation in aq. solutions, despite a modest brightness value. If we are completely honest, we must also mention that a slow degradation of this $\mathrm{N}$ oxide-based fluorophore was noted during its prolonged solidstate storage at $4{ }^{\circ} \mathrm{C}$ (ca. $10 \%$ of degradation based on a RPHPLC analysis after 12 months) to give several unidentified products lacking absorption within the visible spectral range. This latter point suggests a degradation pathway involving a ringopening process and leading to disruption of the $\pi$-conjugation of the phenoxazine chromophore. This hypothesis will be strengthened by further investigations aimed at characterizing spectrospically the degradation products.

Wet synthesis of phenoxazine dye 8 and its $\mathrm{N}$-oxide derivative 7. "Turn-on" fluorogenic detection of NO

In addition to its marked reactivity towards nitrosating agents (vide supra), the lack of both visible color absorbance and fluorescence properties for diaryl ether analog 4 then led us to evaluate this structurally simple molecule as a zero-background fluorescent probe for gasotransmitter NO. This ubiquitous cellular signaling molecule is involved in various metabolic pathways and its abnormal levels are often associated with pathological states of various diseases (e.g., cardiovascular diseases ${ }^{[35]}$, asthma, cancer, neurodegenerative disorders, ...). Consequently, due to this pivotal role, several direct or indirect methods for detecting and quantifying NO levels in different biological matrices have been developed. Among these, those based on electrochemical, optical and/or nanoscale sensors/probes are often regarded as promising approaches for accurate and real-time bioimaging of NO, with the aim of facilitating robust biomedical or clinical translational applications (i.e., clinical diagnostics). ${ }^{[35]}$ In the field of small-molecule fluorescent probes responsive to this gasotransmitter ${ }^{[36]}$, a major breakthrough was achieved by Anslyn and Yang through the design of highly selective low-background imaging agents based on the "covalent-assembly" principle (see introduction section and Figure 2). Indeed, they discovered that non-emissive 2-aminobiphenyl scaffolds were able to selectively create green-yellow-emitting fluorophores based on benzo[c]cinnoline heterocycle, upon their reaction with $\mathrm{N}_{2} \mathrm{O}_{3}$ (oxidized surrogate of $\mathrm{NO}$ ) and under physiological conditions. ${ }^{\text {[19a- }}$ c] However, despite a comprehensive structure-property relationship study aimed at optimizing spectral properties of in situ formed benzo[c]cinnoline derivative, they did not manage to identify a candidate suitable for in vivo detection of NO within the NIR-I spectral region. In order to fill this gap and to rapidly establish a proof-of-concept, we wished to study the fluorogenic behavior of bis(3-dimethylaminophenyl) ether $\mathbf{4}$ in the presence of gasotransmitter NO. From a practical point of view, a fresh aq. solution of NO was prepared using a literature procedure and its concentration was determined to be $10.7 \mathrm{mM}$ by the Griess method $^{[37]}$. Fluorogenic $\mathrm{NO}$ assays and blank experiments were achieved through time-course measurements. Ultrapure water was chosen as aq. medium because our preliminary attempts conducted with phosphate buffer (PB, $100 \mathrm{mM}, \mathrm{pH}$ 7.6) or HEPES buffer $(50 \mathrm{mM}, \mathrm{pH} 7.4)$ failed undoubtedly by virtue of a too rapid degradation of NO. As shown in Figure $5 \mathrm{~A}$ and unsurprising, probe 4 displayed an ultra-low background fluorescence, typical of xanthene-based "covalent-assembly" fluorescent probes; upon incubated with different amounts of NO (25 to 300 equiv.), a dramatic and gradual increase of NIR-I fluorescence signal was observed, indicating the continuous incremental formation of $\mathrm{N}$ oxide derivative 7 in solution (Ex/Em 685/730 nm). Furthermore, a good overlay between the emission spectrum of solution, recorded after $25 \mathrm{~min}$ of incubation with $\mathrm{NO}$, and the emission curve of pure fluorophore independently synthesized through the $\mathrm{NOBF}_{4}$ procedure (vide supra), was obtained (Figure $5 \mathrm{~B}$ ). This positive result supports our initial hypothesis whereby in situ formation of a phenoxazine core is able to take place in water, initially triggered by NO-mediated $\mathrm{C}$-nitrosation and completed by an electronic cascade involving the phenylogous amine (Figure 3 ). Depending on the excess of the nitrosating agent added to the 
aq. solution of 4 , the plateau was reached within a time range of 10 to $20 \mathrm{~min}$. An additional spectroscopic evidence of the effective synthesis of this fluorescent heterocycle in water, was the rapid coloration of the probe solution in blue-green upon addition of reactive analyte (see Figure $\mathrm{S} 1$ ). Therefore, this probe design principle may also be applicable to chromogenic "naked eye" detection of NO or related nitrosating agents. Since heterocyclic $\mathrm{N}$-oxide derivatives are known to be prone to facile reduction (i.e., deoxygenation), we actually think that in situ formed fluorophore 7 could be wholly or partly converted into phenoxazine 8 depending on the redox status of the medium in which its NOsensitive precursor 4 would be used. ${ }^{[21]}$ Consequently, a dualchannel fluorescence detection/imaging scheme should be preferred for the simultaneous visualization of the two emissive species possibly formed. To verify both formation of phenoxazine 8 under mild reducing conditions and the possibility of its real-time detection using a more suitable set of Ex/Em parameters (Ex/Em $650 / 675 \mathrm{~nm}$ ), we performed further kinetic experiments involving one-pot sequential incubation with NO (50 equiv., $25 \mathrm{~min}$ of incubation) and a water-soluble reductant (i.e., tris(2carboxyethyl)phosphine (TCEP) 170 equiv., or NADH 140 equiv.). The spectral changes observed on both $\mathrm{N}$-oxide and phenoxazine channels (Figure 6), when "covalent-assembly" type probe $\mathbf{4}$ was subjected successively to the nitrosating agent and phosphine, clearly confirm the facile reduction of 7 and its conversion into phenoxazine 8. Indeed, over the course of $10 \mathrm{~min}$, the fluorescence emission intensity at $730 \mathrm{~nm}$ steadily decreased and that centered at $675 \mathrm{~nm}$ steadily increased. More disappointing results were obtained from experiments conducted with NADH because fluorescence time-course measurements reveal chemical inertness of $\mathrm{N}$-oxide derivative 7 towards this biocompatible hydride source, at least in the non-buffered conditions chosen for our in vitro validations. To confirm that fluorescence signal changes observed during the activation kinetics of probe 4 were due to the in situ formation of phenoxazine heterocycles $\mathbf{7}$ and $\mathbf{8}$, each reaction mixture was subjected to RP-HPLC-fluorescence analyses (Figure 7 for selected examples). For each sample collected from the reactions with $\mathrm{NO}$ alone, a single peak was detected $\left(t_{\mathrm{R}}=3.45 \mathrm{~min}\right.$ ) on the channel Ex/Em 685/730 nm, and unambiguously assigned to the expected $\mathrm{N}$-oxide fluorophore (co-injection with an authentic sample of 7). Interestingly, a second peak with a lower retention time $\left(t_{R}=3.36 \mathrm{~min}\right)$ was observed but only on the phenoxazine channel Ex/Em 650/675 nm, and identified as being the deoxygenated analog (again, through co-injection with an authentic sample of $\mathbf{8}$ ). It may be surprising to detect phenoxazine 8 in mixtures not containing a reducing agent even its formation rate is limited. One hypothesis based on a photoreduction process promoted by the long-time irradiation required for kinetics measurements, can be put forward to explain the unexpected formation of $\mathbf{8}^{[38]}$ Furthermore, since the fluorescence quantum yield of this fluorophore is much higher than that of its $\mathrm{N}$-oxide precursor 7, detection on channel Ex/Em 650/675 nm was dramatically maximized. For kinetics involving sequential incubations of $\mathbf{4}$ with $\mathrm{NO}$ and TCEP, the disappearance of $\mathrm{N}$-oxide peak at $t_{R}=3.45 \mathrm{~min}$ and the increase of phenoxazine peak height $\left(t_{R}=3.36 \mathrm{~min}\right)$ were observed. These results are fully consistent with those arising from fluorescence time-course measurements and confirm the facile deoxygenation of 7 under mild aq. reducing conditions. Finally, in order both to provide a further evidence for the claimed detection mechanism and to evaluate the conversion rate of the fluorogenic cascade reaction occurring in pure water, the same mixtures were analyzed by RP-HPLC-MS (Figure 8 for selected examples). Several valuable observations and conclusions have been drawn: (1) the disappearance of the starting "covalent-assembly" probe 4 peak $\left(t_{R}=4.22 \mathrm{~min}\right)$ is clearly observed whatever the excess of NO used, thus confirming the high reactivity of this diaryl ether analog towards this nitrosating reagent; (2) the formation of several products, the three main ones being the targeted $\mathrm{N}$-oxide phenoxazine dye 7 $\left(t_{\mathrm{R}}=3.44 \mathrm{~min}, \lambda_{\max }=679 \mathrm{~nm}, \mathrm{MS}(\mathrm{ESI}+): \mathrm{m} / \mathrm{z}=284.3[\mathrm{M}]^{+}\right.$, calcd for $\mathrm{C}_{16} \mathrm{H}_{18} \mathrm{~N}_{3} \mathrm{O}_{2}{ }^{+} 284.1$ ) and two isomeric bis-nitro derivatives of bis(3-dimethylaminophenyl) ether $\left(t_{R}=5.04\right.$ and $5.28 \mathrm{~min}, \lambda_{\max }=$ 396 and $438 \mathrm{~nm}, \mathrm{MS}(\mathrm{ESI}+): \mathrm{m} / \mathrm{z}=347.0[\mathrm{M}+\mathrm{H}]^{+}$, calcd for $\mathrm{C}_{16} \mathrm{H}_{19} \mathrm{~N}_{4} \mathrm{O}_{5}{ }^{+}$347.1) showing that NO-mediated nitrosation reaction is not univocal and therefore that the phenoxazine-based fluorophore scaffold construction is not a quantitative process. The same analytical methodology applied to samples having undergone a further reduction step also provided interesting mechanistic information (Figure 9 for selected examples). Indeed, as expected, incubation with a large excess of TCEP resulted in disappearance of the peak of $\mathrm{N}$-oxide 7 and appearance of a new one at $t_{\mathrm{R}}=3.35 \mathrm{~min}$ unambiguously assigned to phenoxazine dye $8\left(\lambda_{\max }=646 \mathrm{~nm}, \mathrm{MS}(\mathrm{ESI}+): \mathrm{m} / \mathrm{z}=268.3[\mathrm{M}]^{+}\right.$, calcd for $\mathrm{C}_{16} \mathrm{H}_{18} \mathrm{~N}_{3} \mathrm{O}^{+}$268.1). Interestingly, the analysis of some crude nitrosation/reduction reaction mixtures also revealed the lack of phenoxazine dye 8 and the presence of a more polar compound $\left(t_{R}=2.25 \mathrm{~min}\right.$ ) with the following spectroscopic signature: $\lambda_{\max }=$ $652 \mathrm{~nm}, \mathrm{MS}(\mathrm{ESI}+): \mathrm{m} / \mathrm{z}=516.4\left[\mathrm{M}^{2+}-\mathrm{H}\right]^{+}$and $258.8[\mathrm{M}]^{2+}$, calcd for $\mathrm{C}_{25} \mathrm{H}_{32} \mathrm{~N}_{3} \mathrm{O}_{7}{ }^{2+} 517.2$, was observed (Figure 9). This compound was assigned to a covalent adduct between fluorophore and TCEP, probably formed through a nucleophilic addition of this phosphine to the $\mathrm{N}$-(4-imino-2,5-cyclohexadien-1-ylidene)- $\mathrm{N}$ methylmethanaminium ring moiety of $\mathbf{8}$ followed by spontaneous oxidation to reform the $\pi$-conjugated system of phenoxazine dye. Even if this phosphonium-based phenoxazine derivative has not yet independently synthesized and its spectral properties determined, we assume that this compound keeps fluorescence properties because it was possible to detect it on the phenoxazine Ex/Em 650/675 nm channel used for RP-HPLC-fluorescence analyses. To the best of our knowledge, this type of oxidative addition reaction has never been studied extensively in the context of phenoxazine dyes, except in the case of resorufin derivatives. Indeed, covalent adducts with $\beta$-mercatpoethanol and enzymes (e.g., sheep liver cytosolic aldehyde dehydrogenase) have been synthesized and fully-characterized, and mechanistic insights into their formation have been gained. [39]

All the collected data allowed us to confirm the viability of the NOsensing mechanism initially claimed even if the novel "covalentassembly" strategy producing far-red/NIR-I active phenoxazine scaffolds, is not a quantitative process, at least, in the selected in vitro conditions. Indeed, NO spontaneously reacts with triplet oxygen to produce a myriad of reactive nitrogen species (RNS) and some of them may be able to nitrate bis-aryl ether $\mathbf{4}$, these reactions being concurrent to the desired nitrosation process as evidenced by RP-HPLC-MS analyses (vide supra). More broadly in the field of reaction-based fluorescent probes, the analytical methodology used above illustrates the need and the utility to systematically combine conventional fluorescence-based assays with complementary HPLC-fluorescence and HPLC-MS analyses, for deciphering precisely the activation mechanism of such sensing molecular tools based on fluorescence modality. 


\section{Conclusions}

In summary, we developed a novel straightforward synthesis of phenoxazine dyes, whose usefulness was illustrated through rapid access to the methyl analog of NIR-I fluorophore oxazine 1 from bis(3-dimethylaminophenyl) ether 4. Compared to synthetic methods commonly employed for preparing these fluorescent $\mathrm{N}, \mathrm{O}$-heterocycles, the main improvement is the use of $\mathrm{NOBF}_{4}$ as nitrosating agent, that facilitates the construction of phenoxazine scaffold under mild neutral conditions and via an $\mathrm{N}$-oxide intermediate; this latter one undergoing a smooth reduction with a phosphine. Therefore, it was easy to implement this domino process in pure water using nitric oxide and a water-soluble phosphine TCEP as biocompatible trigger and reductant respectively. Since both reactions (i.e., nitrosation/cyclization and deoxygenation of heteroyclic $\mathrm{N}$-oxide) cause dramatic changes in the spectral properties of starting non-fluorescent and UVabsorbing diaryl ether analog 4, these could be advantageously utilized for construction of high-performance "OFF-ON" fluorescent probes for monitoring NO in living biological systems. Depending on the cellular redox state, and possible interactions of NO with biologically relevant thiols (i.e., cysteine, homocysteine and glutathione $)^{[40]}$, a dual-channel fluorescence signal readout strategy based on simultaneous or sequential detection of $\mathrm{N}$ oxide 7 and phenoxazine 8 , will be considered. ${ }^{[41]}$ Within this context, our work is the first example of "covalent-assembly" type probe that yields far-red/NIR-I fluorescent molecules in water and through an intramolecular cascade reaction triggered by a biorelevant analyte (or at least, its oxidized surrogate $\mathrm{N}_{2} \mathrm{O}_{3}$ ). Interestingly, during the course of our study, another "covalentassembly" approach for NIR-I fluorescence sensing of nerve agent mimic diethyl chlorophosphate (DCP) in organic media (DMSO) was proposed by Vijay et al. ${ }^{[42]}$ Indeed, in situ formation of a coumarin fused pyronin hybrid dye from a 4-aryloxy derivative of 7-(diethylamino)-3-formylcoumarin, through a chemical cascade triggered by DCP, causes large bathochromic shifts in both absorption (from 263/368 $\mathrm{nm}$ to $600 \mathrm{~nm}$ ) and emission maxima (from $585 \mathrm{~nm}$ to $658 \mathrm{~nm}$ ), enabling the rapid and facile ratiometric detection of this electrophilic phosphorus compound in various matrices including soil samples and living cells (Figure 10) These two pioneering contributions show quite clearly the potential benefits to be gained by designing NIR-I "covalentassembly" fluorescent probes and should therefore stimulate research efforts in this direction. To achieve this ambitious goal, organic chemists will have a key role to play, through the discovery of novel cascade chemical transformations, often biocompatible and leading to $\pi$-extended push-pull molecules.

\section{Experimental Section}

\section{General}

Unless otherwise noted, all commercially available reagents and solvents were used without further purification. TLC was carried out on Merck Millipore DC Kieselgel 60 F-254 aluminum sheets. The spots were directly visualized or through illumination with a UV lamp ( $\lambda=254 / 365 \mathrm{~nm}$ ). Purifications by flash-column chromatography were performed on silica gel $(40-63 \mu \mathrm{m})$ from VWR. Acetonitrile (MeCN, RE grade, \#P0060268) from Carlo Erba was used for both syntheses (i.e., reaction involving $\mathrm{NOBF}_{4}$ ) and purifications by semi-preparative HPLC. Anhydrous DMSO was purchased from Carlo Erba, and stored over $3 \AA$ molecular sieves, and UV-spectroscopy grade DMSO was provided by Honeywell Riedel-deHaën. $\mathrm{CHCl}_{3}$ (for spectroscopy, \#167730010), purchased from Acros Organics, and absolute $\mathrm{EtOH}(>99.8 \%)$ from Honeywell Riedel-de Haën were used for spectral measurements. TFA (HPLC grade, +99\%) was provided by Fisher Chemical. Formic acid (FA, puriss p.a., ACS reagent, reag. Ph. Eur., $\geq 98 \%$ ) was provided by Merck Millipore (Sigma-Aldrich brand). The HPLC-gradient grade MeCN was obtained from Carlo Erba or Fisher Chemical. All aqueous buffers used in this work and aqueous mobile-phases for HPLC were prepared using water purified with a PURELAB Ultra system from ELGA (purified to $18.2 \mathrm{M} \Omega . \mathrm{cm}$ ). 8Bromojulolidine [64230-25-7], dimethyldiarylsilane DAEA-Si 6 [210195880-7] and aza-BODIPY dye (BF2 chelate of [5-(4-methoxyphenyl)-3phenyl-1H-pyrrol-2-yl]-[5-(4-methoxyphenyl)-3-phenyl-pyrrol-2-ylidene]amine) [490035-88-6] were prepared according to literature procedures. ${ }^{[26-}$ $27,43]$

\section{Instruments and methods}

Freeze-drying operations were performed with a Christ Alpha 2-4 LD plus Centrifugation steps were performed with a Thermo Scientific Espresso Personal Microcentrifuge instrument. ${ }^{1} \mathrm{H}-{ }^{13} \mathrm{C}$ - and ${ }^{19} \mathrm{~F}-\mathrm{NMR}$ spectra were recorded on a Bruker Avance $\mathrm{Neo} 500 \mathrm{MHz}$ (equipped with a $5 \mathrm{~mm}$ BBOF iProbe). Chemical shifts are expressed in parts per million (ppm) from the residual non-deuterated solvent signal. ${ }^{44]} J$ values are expressed in $\mathrm{Hz}$. IR spectra were recorded with a Bruker Alpha FT-IR spectrometer equipped with a universal ATR sampling accessory. The bond vibration frequencies are expressed in reciprocal centimeters $\left(\mathrm{cm}^{-1}\right)$. HPLC-MS analyses were performed on a Thermo-Dionex Ultimate 3000 instrument (pump + autosampler at $20^{\circ} \mathrm{C}+$ column oven at $25^{\circ} \mathrm{C}$ ) equipped with a diode array detector (Thermo-Dionex DAD 3000-RS) and MSQ Plus single quadrupole mass spectrometer. Purifications by semi-preparative HPLC were performed on a Thermo-Dionex Ultimate 3000 instrument (semipreparative pump HPG-3200BX) equipped with an RS Variable Detector (VWD-3400RS, four distinct wavelengths within the range 190-800 nm). lon chromatography analyses (for the determination of TFA or $\mathrm{BF}_{4}^{-}$mass content in samples) were performed using a Thermo Scientific Dionex ICS 5000 ion chromatograph equipped with a conductivity detector CD (Thermo Scientific Dionex) and a conductivity suppressor ASRS-ultra II 4 $\mathrm{mm}$ (Thermo Scientific Dionex), and according to a method developed by the PACSMUB staff. Low-resolution mass spectra (LRMS) were recorded on a Thermo Scientific MSQ Plus single quadrupole equipped with an electrospray (ESI) source (LC-MS coupling). UV-visible spectra were obtained either on a Varian Cary 50 Scan or on a Agilent Cary 60 (singlebeam) spectrophotometer (software Cary WinUV) by using a rectangular quartz cell (Hellma, 100-QS, $45 \times 12.5 \times 12.5 \mathrm{~mm}$, pathlength: $10 \mathrm{~mm}$, chamber volume: $3.5 \mathrm{~mL}$ ), at $25{ }^{\circ} \mathrm{C}$ (using a temperature control system combined with water circulation). The absorption spectra of phenoxazine dyes were recorded in the corresponding solvent within the concentration range 5-20 $\mu \mathrm{M}$ (three distinct dilutions for the accurate determination of molar extinction coefficients). The vast majority of fluorescence spectra were recorded on an HORIBA Jobin Yvon Fluorolog spectrofluorometer (software FluorEssence) at $25{ }^{\circ} \mathrm{C}$ (using a temperature control system combined with water circulation), with a standard fluorometer cell (Labbox, LB Q, light path: $10 \mathrm{~mm}$, width: $10 \mathrm{~mm}$, chamber volume: $3.5 \mathrm{~mL}$ ). The following set of parameters was used: shutter: Auto Open, Ex/Em slits $=5$ $\mathrm{nm}$ for recording emission spectra and Ex/Em slits $=5 \mathrm{~nm}$ for recording excitation spectra, integration time $=0.1 \mathrm{~s}, 1 \mathrm{~nm}$ step, $\mathrm{HV}(\mathrm{S} 1)=950 \mathrm{~V}$. All fluorescence spectra were corrected. Relative fluorescence quantum yields were measured in the corresponding buffer at $25^{\circ} \mathrm{C}$ by a relative method using the suitable standard (aza-BODIPY dye: $\Phi_{\mathrm{F}}=36 \%$ in $\mathrm{CHCl}_{3}$, excitation at $630 \mathrm{~nm}^{[43]}$ or Nile Blue: $\Phi_{\mathrm{F}}=27 \%$ in $\mathrm{EtOH}$, excitation at 600 $\mathrm{nm}^{[33]}$; dilution by a factor $\times 3$ between absorption and fluorescence measurements). The following equation was used to determine the relative fluorescence quantum yield:

$$
\Phi_{F}(x)=\left(A_{S} / A_{X}\right)\left(F_{X} / F_{S}\right)\left(n_{X} / n_{S}\right)^{2} \Phi_{F}(s)
$$

where $A$ is the absorbance (in the range of 0.01-0.1 A.U.), $F$ is the area under the emission curve, $n$ is the refractive index of the solvents (at $25^{\circ} \mathrm{C}$ ) used in measurements, and the subscripts $s$ and $x$ represent standard and unknown, respectively. The following refractive indices were used: 1.337 for PB, 1.333 for water, aq. 0.1\% FA and HEPES buffer, 1.362 for EtOH, 1.489 for $\mathrm{CHCl}_{3}$, and 1.478 for DMSO. Fluorescence-based kinetic assays were performed on a SAFAS FIx-Xenius XC spectrofluorimeter using quartz cells (SAFAS, Quartz Suprasil for SAFAS flx Xenius, $45 \times 12.5 \times$ $12.5 \mathrm{~mm}$, pathlength: $10 \mathrm{~mm}$, chamber volume: $3.5 \mathrm{~mL}$ ), at $25^{\circ} \mathrm{C}$ (using a temperature control system combined with water circulation). The following set of parameters was used: Ex/Em bandwidth $=5 \mathrm{~nm}$, integration time $=0.5 \mathrm{~s}$, and tunable PMT voltage. All fluorescence spectra were corrected.

High-performance liquid chromatography separations

Several chromatographic systems were used for the analytical experiments (HPLC-MS) and the purification steps: System A: RP-HPLC- 
MS (Phenomenex Kinetex $\mathrm{C}_{18}$ column, $2.6 \mu \mathrm{m}, 2.1 \times 50 \mathrm{~mm}$ ) with $\mathrm{MeCN}$ $(+0.1 \% \mathrm{FA})$ and $0.1 \%$ aqueous formic acid (aqueous $\mathrm{FA}, \mathrm{pH} 2.1)$ as eluents [5\% MeCN (0.1 $\mathrm{min}$ ) followed by linear gradient from $5 \%$ to $100 \%$ $(5 \mathrm{~min}$ ) of $\mathrm{MeCN}$, then $100 \% \mathrm{MeCN}(1.5 \mathrm{~min})]$ at a flow rate of $0.5 \mathrm{~mL} / \mathrm{min}$ UV-visible detection was achieved at 220, 260, 645 and $680 \mathrm{~nm}$ (+diode array detection in the range of 220-700 nm). Low resolution ESI-MS detection in the positive/negative mode (full scan, 100-1000 a.m.u., data type: centroid, needle voltage: $3.0 \mathrm{kV}$, probe temperature: $350{ }^{\circ} \mathrm{C}$, cone voltage: $75 \mathrm{~V}$ and scan time: $1 \mathrm{~s}$ ). System B: semi-preparative RP-HPLC (SiliCycle SiliaChrom $\mathrm{C}_{18}$ column, $10 \mu \mathrm{m}, 20 \times 250 \mathrm{~mm}$ ) with $\mathrm{MeCN}$ and aq. $0.1 \mathrm{TFA}(\mathrm{pH} 1.9)$ as eluents [ $10 \% \mathrm{MeCN}$ ( $5 \mathrm{~min}$ ), followed by a gradient of $10 \%$ to $20 \% \operatorname{MeCN}(7.5 \mathrm{~min})$, then $20 \%$ to $100 \% \mathrm{MeCN}(93 \mathrm{~min})]$ at a flow rate of $20.0 \mathrm{~mL} / \mathrm{min}$. Quadruple UV-visible detection was achieved at 220, 270, 645 and $700 \mathrm{~nm}$. System C: RP-HPLC-fluorescence (Phenomenex Kinetex $\mathrm{C}_{18}$ column, $2.6 \mu \mathrm{m}, 2.1 \times 50 \mathrm{~mm}$ ) with same eluents and gradient as system A. Fluorescence detection was achieved at $45^{\circ} \mathrm{C}$ at the following Ex/Em channels: $650 / 675 \mathrm{~nm}$, and $685 / 730 \mathrm{~nm}$ (sensitivity: 1, PMT Auto, filter wheel: Auto). System D: system A with UVvisible detection at 220,260,650 and $680 \mathrm{~nm}$ (+diode array detection in the range 220-800 $\mathrm{nm}$ ). Low resolution ESI-MS detection in the positive/negative modes (full scan, 100-1000 a.m.u., data type: centroid needle voltage: $3.0 \mathrm{kV}$, probe temperature: $350^{\circ} \mathrm{C}$, cone voltage: $75 \mathrm{~V}$ and scan time: $1 \mathrm{~s}$ ).

\section{Syntheses}

\section{Bis(3-dimethylaminophenyl) ether 4 [867020-61-9]}

A mixture of 3-(dimethylamino)phenol (162 mg, $1.18 \mathrm{mmol}, 1$ equiv.), 3bromo- $N, N$-dimethylaniline (558 mg, $4.28 \mathrm{mmol}, 3.6$ equiv.), finely ground anhydrous $\mathrm{K}_{3} \mathrm{PO}_{4}(732 \mathrm{mg}, 3.54 \mathrm{mmol}, 3$ equiv.), Cul (33 mg, $0.27 \mathrm{mmol}$ 0.15 equiv.) and picolinic acid ( $43 \mathrm{mg}, 0.35 \mathrm{mmol}, 0.3$ equiv.) in dry DMSO $(4.2 \mathrm{~mL})$ was heated in a sealed tube at $130{ }^{\circ} \mathrm{C}$ overnight. The reaction was checked for completion by TLC (eluent: heptane/DCM 1:1, v/v) and diluted with EtOAc. Thereafter, the resulting organic phase was washed twice with brine, dried over anhydrous $\mathrm{MgSO}_{4}$, filtered and concentrated under reduced pressure. The resulting residue was purified by flashcolumn chromatography over silica gel (eluent: heptane/DCM 1:1, v/v) to give the desired product as pinkish amorphous powder $(227 \mathrm{mg}, 0.89$ mmol, yield 75\%). IR (ATR): $v=3061,3028,2884,2844,2799,2209,2073$ 1950, 1924, 1885, 1605, 1576, 1563, 1496, 1442, 1356, 1324, 1228, 1168 $1151,1123,1062,1004,871,850,833,449,748,725 ;{ }^{1} \mathrm{H}$ NMR $(500 \mathrm{MHz}$ $\left.\mathrm{CDCl}_{3}\right): \delta=7.17(\mathrm{t}, J=8.0 \mathrm{~Hz}, 2 \mathrm{H}), 6.52-6.43(\mathrm{~m}, 4 \mathrm{H}), 6.37$ (ddd, $J=8.0$ $\mathrm{Hz}, J=2.2 \mathrm{~Hz}, J=0.8 \mathrm{~Hz}, 2 \mathrm{H}), 2.94(\mathrm{~s}, 12 \mathrm{H}) ;{ }^{13} \mathrm{C} \mathrm{NMR}\left(126 \mathrm{MHz}, \mathrm{CDCl}_{3}\right)$ $\delta=158.5,152.2,129.9,107.5,106.9,103.5,40.7 ; \mathrm{HPLC}\left(\right.$ system A): $t_{\mathrm{R}}=$ 4.2 min (purity $>99 \%$ at $260 \mathrm{~nm}$ ): LRMS (ESI+, recorded during RP-HPLC analysis): $m / z 257.4[\mathrm{M}+\mathrm{H}]^{+}(100)$ and $298.4[\mathrm{M}+\mathrm{H}+\mathrm{MeCN}]^{+}$(70), calcd for $\mathrm{C}_{16} \mathrm{H}_{21} \mathrm{~N}_{2} \mathrm{O}^{+} 257.2$

\section{$\mathrm{N}$-Oxide phenoxazine dye 7}

To a solution of symmetrical diaryl ether analog $4(100 \mathrm{mg}, 0.39 \mathrm{mmol}$, equiv.) in $\mathrm{MeCN}(5 \mathrm{~mL})$, was added $\mathrm{NOBF}_{4}(46 \mathrm{mg}, 0.39 \mathrm{mmol}, 1$ equiv.) The resulting reaction mixture was stirred at RT for $5 \mathrm{~min}$. Afterwards, the reaction mixture was concentrated under reduced pressure and the residue diluted with deionized $\mathrm{H}_{2} \mathrm{O}$. This aqueous mixture was extracted with DCM and DCM/iPrOH $(1: 1, \mathrm{v} / \mathrm{v})$. The combined organic layers were dried over anhydrous $\mathrm{MgSO}_{4}$, filtered and concentrated under reduced pressure. The resulting residue was purified by flash-column chromatography over silica gel (a step gradient of $\mathrm{MeOH}$ in $\mathrm{DCM}$ from $0 \%$ to $2 \%$ ) to give the desired product as dark blue amorphous powder (36 mg, $97 \mu \mathrm{mol}$, yield $25 \%$ based on $\mathrm{BF}_{4}^{-}$mass $=23.6 \%$ determined by ionic chromatography). IR (ATR): $v=3564,3088,2923,1636,1595,1523,1488$ 1435, 1390, 1364, 1330, 1283, 1181, 1120, 1031, 928, 862, 825, 760; ${ }^{1} \mathrm{H}$ NMR (500 MHz, [D 6 ] DMSO): $\delta=8.09(\mathrm{~d}, J=9.8 \mathrm{~Hz}, 2 \mathrm{H}), 7.29(\mathrm{dd}, J=9.8$ $\mathrm{Hz}, J=2.6 \mathrm{~Hz}, 2 \mathrm{H}), 6.85(\mathrm{~d}, J=2.5 \mathrm{~Hz}, 2 \mathrm{H}), 3.32(\mathrm{~s}, 12 \mathrm{H}) ;{ }^{13} \mathrm{C}$ NMR $(126$ $\left.\mathrm{MHz},\left[\mathrm{D}_{6}\right] \mathrm{DMSO}\right): \delta=156.4,152.0,125.8,122.3,116.3,95.7,41.0 ;{ }^{19} \mathrm{~F}$ NMR (470 MHz, [D6]DMSO): $\delta=-148.3\left(\mathrm{~d}, J=2.2 \mathrm{~Hz}, 4 \mathrm{~F}, \mathrm{~B} F_{4}{ }^{-}\right)$; HPLC (system A): $t_{R}=3.36$ min (purity $>97 \%$ at $260 \mathrm{~nm},>99 \%$ at $645 \mathrm{~nm}$ and $>99 \%$ at $680 \mathrm{~nm}$ ); LRMS (ESI+, recorded during RP-HPLC analysis): $\mathrm{m} / \mathrm{z}$ $284.4[\mathrm{M}]^{+}(100)$, calcd for $\mathrm{C}_{16} \mathrm{H}_{18} \mathrm{~N}_{3} \mathrm{O}_{2}+284.1$

\section{Phenoxazine dye 8}

To a solution of $\mathrm{N}$-oxide phenoxazine dye $8(15 \mathrm{mg}, 40 \mu \mathrm{mol}, 1$ equiv.) in MeCN (1 mL), was added $\mathrm{PPh}_{3}(13 \mathrm{mg}, 0.05 \mathrm{mmol}, 1.2$ equiv.). The resulting reaction mixture was stirred at $R T$ for $2 \mathrm{~h}$. The reaction was checked for completion by RP-HPLC-MS (system A) and diluted with aq $0.1 \%$ TFA. The resulting solution was directly purified by semi-preparative RP-HPLC (system B, $t_{R}=22.0-28.0 \mathrm{~min}$ ). The product containing fractions were lyophilized to give the desired product as dark blue amorphous powder $(14 \mathrm{mg}, 26 \mu \mathrm{mol}$, yield $65 \%$ based on TFA mass $=50.04 \%$ determined by ionic chromatography). IR (ATR): $v=2929,1777,1727$,
1693, 1651, 1601, 1503, 1491, 1396, 1345, 1179, 1126, 1061, 912, 887 $855,827,787 ;{ }^{1} \mathrm{H}$ NMR $\left(500 \mathrm{MHz},\left[\mathrm{D}_{6}\right] \mathrm{DMSO}\right): \delta=7.79(\mathrm{~d}, J=9.6 \mathrm{~Hz}, 2 \mathrm{H})$ $7.41(\mathrm{dd}, J=9.6 \mathrm{~Hz}, J=2.7 \mathrm{~Hz}, 2 \mathrm{H}), 6.93(\mathrm{~d}, J=2.7 \mathrm{~Hz}, 2 \mathrm{H}), 3.38(\mathrm{~s}$, 12H); ${ }^{13} \mathrm{C}$ NMR (126 MHz, D 6 JMSO): $\delta=157.2,148.5,133.8,133.6$ 117.6, 96.3, 41.3; ${ }^{19} \mathrm{~F}$ NMR $\left.\left(470 \mathrm{MHz}, \mathrm{D}_{6}\right] \mathrm{DMSO}\right): \delta=-74.3\left(\mathrm{~s}, 3 \mathrm{~F}, \mathrm{CF}_{3-}\right.$ TFA); HPLC (system A): $t_{R}=3.25$ min (purity $>99 \%$ at $260 \mathrm{~nm},>99 \%$ at $645 \mathrm{~nm}$ and $>99 \%$ at $680 \mathrm{~nm}$ ); LRMS (ESI+, recorded during RP-HPLC analysis): $m / z 268.4[\mathrm{M}]^{+}(100)$, calcd for $\mathrm{C}_{16} \mathrm{H}_{18} \mathrm{~N}_{3} \mathrm{O}^{+} 268.1$.

In vitro activation of "covalent-assembly fluorescent probe 4 by NO

Experimental details about stock solutions of probe and reactive analytes

- Solution A: a stock solution of probe $4(1.0 \mathrm{mg} / \mathrm{mL}, 3.9 \mathrm{mM})$ in DMSO (UV-spectroscopy grade).

- Solution B: a $10.7 \mathrm{mM}$ solution of NO, prepared according to the protocol described in the literature.[37a]

- Solution C: solution of TCEP $(140 \mathrm{mM})$ in ultrapure $\mathrm{H}_{2} \mathrm{O}$, directly used without dilution. Commercial TCEP hydrochloride (Acros Organics, \#363630010) was used to prepare this solution as follows: $4.92 \mathrm{mg}$ in 1227 $\mu \mathrm{L}$ of ultrapure $\mathrm{H}_{2} \mathrm{O}$ and subsequent neutralization with aq. $10 \mathrm{M} \mathrm{NaOH}$. - Solution D: solution of NADH (Sigma, \#43420-1G, $140 \mathrm{mM}$ ) in ultrapure $\mathrm{H}_{2} \mathrm{O}(6.62 \mathrm{mg}$ in $666 \mu \mathrm{L})$, directly used without dilution.

\section{Fluorescence-based assays}

All assays were performed at $25^{\circ} \mathrm{C}$ (using a temperature control system combined with water circulation) and conducted under continuous mechanical stirring through the use of small stirrer blades. Solution A $(6.4$ $\mu \mathrm{L}$ ) was mixed with $2.5 \mathrm{~mL}$ of ultrapure water in $3.5 \mathrm{~mL}$ fluorescence quartz cell (final concentration of probe 4: $10 \mu \mathrm{M}$ ). Fluorescence emission at Ex/Em 685/730 nm (bandwidth $=5 \mathrm{~nm}, \mathrm{PMT}=600 \mathrm{~V}$ ) was recorded every $10 \mathrm{~s}$. After $5 \mathrm{~min}$, the selected volume of solution $\mathrm{B}$ (corresponding to the number of NO equiv. to add) was added and the recording of NIR-I fluorescence signal continued for 15-20 min. Experiments involving sequential addition/incubation with NO and reducing agent (TCEP or $\mathrm{NADH}$, solutions $\mathrm{C}$ and $\mathrm{D}$ ) were achieved in the same manner but the detection of phenoxazine dye 8 also required the use of a second set of parameters $\mathrm{Ex} / \mathrm{Em} 650 / 675 \mathrm{~nm}$ (bandwidth $=5 \mathrm{~nm}, \mathrm{PMT}=600 \mathrm{~V}$, dual measurement at $\mathrm{Ex} / \mathrm{Em} 685 / 730 \mathrm{~nm}$ and $\mathrm{Ex} / \mathrm{Em} 650 / 675 \mathrm{~nm}$ respectively, every $25 \mathrm{~s}$ ). Before and after each kinetic experiment, fluorescence emission spectrum (scan mode) of solution was recorded using the following parameters: Ex at $630 \mathrm{~nm}$ (bandwidth $=5 \mathrm{~nm}$ ), Em within the range $640-950 \mathrm{~nm}$ (bandwidth $=5 \mathrm{~nm}$ ), $1 \mathrm{~nm}$ step, full filtering, and average time $=0.1 \mathrm{~s}$. Please note: the availability of a 10 quartz cell rack on SAFAS FIX-Xenius XC spectrofluorimeter enables to achieve several kinetics at the same time. Blank experiments to assess the stability of the probe 4 in $\mathrm{H}_{2} \mathrm{O}$ and in presence of reducing agents, were achieved in the same way.

$R P$-HPLC-fluorescence and RP-HPLC-MS (full scan mode) analyses Crude solutions from fluorescence-based assays were directly analyzed by RP-HPLC-fluorescence (injected volume: $10 \mu \mathrm{L}$, system C) and RPHPLC-MS (injected volume: $20 \mu \mathrm{L}$, system D). Pure samples of $\mathrm{N}$-oxide 7 and phenoxazine dye $8\left(10 \mu \mathrm{M}\right.$ solution prepared in ultrapure $\left.\mathrm{H}_{2} \mathrm{O}\right)$ were analyzed under the same conditions. For "co-injection" analyses, $250 \mu \mathrm{L}$ of crude solutions from fluorescence-based assays (vide supra) were combined to $250 \mu \mathrm{L}$ of reference solutions (pure sample of 7 or 8 ), and 10 or $20 \mu \mathrm{L}$ of the mix was injected into the HPLC-fluorescence/MS apparatus (systems $\mathrm{C}$ and $\mathrm{D}$ ).

\section{Acknowledgements}

This work is part of the project "'Pharmacoimagerie et Agents Theranostiques", supported by the Universite de Bourgogne and Conseil Régional de Bourgogne through the Plan d'Actions Régional pour I'Innovation (PARI) and the European Union through the PO FEDER-FSE Bourgogne 2014/2020 programs. Financial supports from the French "Investissements d'Avenir" program, project ISITE BFC (contract ANR-15-IDEX-0003), especially for the post-doc fellowship of Dr. Sébastien Jenni, and Agence Nationale de la Recherche (ANR, AAPG 2018, PRCI, LuminoManufacOligo, ANR-18-CE07-0045), especially for the post-doc fellowship of Dr. Kévin Renault are also greatly 
acknowledged. GDR CNRS "Agents d'Imagerie Moléculaire" (AIM) 2037 is also thanked for its interest in this research topic. The authors thank the "Plateforme d'Analyse Chimique et de Synthèse Moléculaire de l'Université de Bourgogne" (PACSMUB, http://www.wpcm.fr) for access to analytical and molecular spectroscopy instruments. COBRA lab (UMR CNRS 6014) and Iris Biotech company are warmly thanked for the generous gift of some chemical reagents used in this work. The authors also thank Dr. Jacques Pliquett (Ph. D. student, 2015-2018, UBFC, ICMUB, P2DA \& OCS teams) for the synthesis of aza-BODIPY dye used as a standard for determination of fluorescence quantum yields, and Prof. Ewen Bodio (University of Burgundy, ICMUB, UMR CNRS 6302, OCS team) for access to SAFAS FIx-Xenius XC spectrofluorimeter.

\section{References}

[1] For selected reviews, see: a) M. lonescu, H. Mantsch, in Advances in Heterocyclic Chemistry, Vol. 8 (Eds.: A. R. Katritzky, A. J. Boulton), Academic Press, 1967, pp. 83-113; b) E. A. Onoabedje, S. A. Egu, M. A. Ezeokonkwo, U. C. Okoro, J. Mol. Struct. 2019, 1175, 956-962.

[2] For a comprehensive review, see: C. O. Okafor, Dyes Pigm. 1986, 7, 103-131.

[3] For a comprehensive review, see: V. Martinez, M. Henary, Chem. - Eur. J. 2016, 22, 13764-13782.

[4] For a comprehensive review, see: J. Jose, K. Burgess, Tetrahedron 2006, 62, 11021-11037.

[5] a) O. A. Kucherak, S. Oncul, Z. Darwich, D. A. Yushchenko, Y. Arntz, P. Didier, Y. Mely, A. S. Klymchenko, J. Am. Chem. Soc. 2010, 132, $4907-$ 4916; b) Z. Darwich, A. S. Klymchenko, O. A. Kucherak, L. Richert, Y Mely, Biochim. Biophys. Acta, Biomembr. 2012, 1818, 3048-3054; c) Z. Darwich, A. S. Klymchenko, D. Dujardin, Y. Mely, RSC Adv. 2014, 4 8481-8488; d) I. A. Karpenko, R. Kreder, C. Valencia, P. Villa, C. Mendre, B. Mouillac, Y. Mely, M. Hibert, D. Bonnet, A. S. Klymchenko, ChemBioChem 2014, 15, 359-363; e) R. Saxena, S. Shrivastava, S. Haldar, A. S. Klymchenko, A. Chattopadhyay, Chem. Phys. Lipids 2014, 183, 1-8; f) R. Kreder, K. A. Pyrshev, Z. Darwich, O. A. Kucherak, Y. Mely, A. S. Klymchenko, ACS Chem. Biol. 2015, 10, 1435-1442; g) D. I. Danylchuk, S. Moon, K. Xu, A. S. Klymchenko, Angew. Chem. Int. Ed. 2019, 58, 14920-14924; h) D. I. Danylchuk, P.-H. Jouard, A. S. Klymchenko, J. Am. Chem. Soc. 2021, 143, 912-924; i) F. Hanser, C. Marsol, C. Valencia, P. Villa, A. S. Klymchenko, D. Bonnet, J. Karpenko, ACS Chem. Biol. 2021, 16, 651-660.

[6] M. Hintersteiner, A. Enz, P. Frey, A.-L. Jaton, W. Kinzy, R. Kneuer, U. Neumann, M. Rudin, M. Staufenbiel, M. Stoeckli, K.-H. Wiederhold, H.U. Gremlich, Nat. Biotechnol. 2005, 23, 577-583.

[7] a) C. M. A. Alves, S. Naik, P. J. G. Coutinho, M. S. T. Gonçalves, Tetrahedron 2009, 65, 10441-10452; b) C. M. A. Alves, S. Naik, P. J. G. Coutinho, M. S. T. Gonalves, Tetrahedron Lett. 2011, 52, 112-116; c) B. Rama Raju, S. Naik, P. J. G. Coutinho, M. S. T. Gonçalves, Dyes Pigm. 2013, 99, 220-227; d) B. R. Raju, M. S. T. Gonçalves, P. J. G. Coutinho, Spectrochim. Acta, Part A 2017, 171, 1-9.

[8] a) K. I. E. McLuckie, Z. A. E. Waller, D. A. Sanders, D. Alves, R. Rodriguez, J. Dash, G. J. McKenzie, A. R. Venkitaraman, S. Balasubramanian, J. Am. Chem. Soc. 2011, 133, 2658-2663; b) S. D. Verma, N. Pal, M. K. Singh, H. Shweta, M. F. Khan, S. Sen, Anal. Chem. 2012, 84, 7218-7226; c) H. Bo, C. Wang, Q. Gao, H. Qi, C. Zhang, Talanta 2013, 108, 131-135; d) Z. Niknezhad, L. Hassani, D. Norouzi, Mater. Sci. Eng., C 2016, 58, 1188-1193; e) V. B. Tsvetkov, A. M. Varizhuk, S. A. Lizunova, T. A. Nikolenko, I. A. Ivanov, V. V. Severov, E. S. Belyaev, E. A. Shitikov, G. E. Pozmogova, A. V. Aralov, Org. Biomol. Chem. 2020, 18, 6147-6154.

[9] For a comprehensive review, see: Y. Tang, D. Lee, J. Wang, G. Li, J. Yu, W. Lin, J. Yoon, Chem. Soc. Rev. 2015, 44, 5003-5015.

[10] a) N.-H. Ho, R. Weissleder, C.-H. Tung, Bioorg. Med. Chem. Lett. 2006, 16, 2599-2602; b) N.-h. Ho, R. Weissleder, C.-H. Tung, Tetrahedron
2006, 62, 578-585; c) N.-H. Ho, R. Weissleder, C.-H. Tung, ChemBioChem 2007, 8, 560-566; d) S. Chen, X. Li, H. Ma, ChemBioChem 2009, 10, 1200-1207; e) J. Lu, Y. Song, W. Shi, X. Li, H. Ma, Sens. Actuators B 2012, 161, 615-620; f) Q. Wan, Y. Song, Z. Li, X. Gao, H. Ma, Chem. Commun. 2013, 49, 502-504; g) L. Li, W. Shi, Z. Wang, Q. Gong, H. Ma, Anal. Chem. 2015, 87, 8353-8359; h) Q. Gong, L. Li, X. Wu, H. Ma, Chem. Sci. 2016, 7, 4694-4697; i) Q. Gong, W. Shi, L. Li, X. Wu, H. Ma, Anal. Chem. 2016, 88, 8309-8314; j) Y. Matsuoka, K. Ohkubo, T. Yamasaki, M. Yamato, H. Ohtabu, T. Shirouzu, S. Fukuzumi, K.-i. Yamada, RSC Adv. 2016, 6, 60907-60915; k) X. He, Y. Xu, W. Shi, H. Ma, Anal. Chem. 2017, 89, 3217-3221; I) Y. Hu, H. Li, W. Shi, H. Ma, Anal. Chem. 2017, 89, 11107-11112; m) Q. Diao, H. Guo, Z. Yang, W. Luo, T. Li, D. Hou, Spectrochim. Acta, Part A 2019, 223, 117284; n) H. Niu, B. Ni, K. Chen, X. Yang, W. Cao, Y. Ye, Y. Zhao, Talanta 2019, 196, 145-152; o) J. Wu, D. Su, C. Qin, W. Li, J. Rodrigues, R. Sheng, L. Zeng, Talanta 2019, 201, 111-118; p) X. Rong, Z.-Y. Xu, J.W. Yan, Z.-Z. Meng, B. Zhu, L. Zhang, Molecules 2020, 25, 4718; q) X.Z. Yang, X.-R. Wei, R. Sun, Y.-J. Xu, J.-F. Ge, Spectrochim. Acta, Part A 2020, 226, 117582.

[11] a) A. Loudet, C. Thivierge, K. Burgess, Dojin News 2011, 137, 1-7; b) J. Fan, M. Hu, P. Zhan, X. Peng, Chem. Soc. Rev. 2013, 42, 29-43.

[12] K. Kolmakov, E. Hebisch, T. Wolfram, L. A. Nordwig, C. A. Wurm, H. Ta, V. Westphal, V. N. Belov, S. W. Hell, Chem. - Eur. J. 2015, 21, 1334413356.

[13] a) J. Jose, K. Burgess, J. Org. Chem. 2006, 71, 7835-7839; b) J. Han, J. Jose, E. Mei, K. Burgess, Angew. Chem. Int. Ed. 2007, 46, 1684-1687; c) J. Jose, Y. Ueno, K. Burgess, Chem. - Eur. J. 2009, 15, 418-423; d) J. Jose, A. Loudet, Y. Ueno, R. Barhoumi, R. C. Burghardt, K. Burgess, Org. Biomol. Chem. 2010, 8, 2052-2059.

[14] a) V. H. J. Frade, M. S. T. Gonçalves, J. C. V. P. Moura, Tetrahedron Lett. 2005, 46, 4949-4952; b) V. H. J. Frade, M. S. T. Gonçalves, J. C. V. P. Moura, Tetrahedron Lett. 2006, 47, 8567-8570; c) V. H. J. Frade, S. A. Barros, J. C. V. P. Moura, P. J. G. Coutinho, M. S. T. Gonçalves, Tetrahedron 2007, 63, 12405-12418; d) V. H. J. Frade, S. A. Barros, J. C. V. P. Moura, M. S. T. Gonçalves, Tetrahedron Lett. 2007, 48, 34033407; e) V. H. J. Frade, P. J. G. Coutinho, J. C. V. P. Moura, M. S. T. Gonçalves, Tetrahedron 2007, 63, 1654-1663; f) V. H. J. Frade, M. S. T. Gonçalves, P. J. G. Coutinho, J. C. V. P. Moura, J. Photochem. Photobiol., A 2007, 185, 220-230; g) A. D. G. Firmino, M. S. T. Gonçalves, Tetrahedron Lett. 2012, 53, 4946-4950; h) B. R. Raju, A. M. F. Garcia, A. L. S. Costa, P. J. G. Coutinho, M. S. T. Gonçalves, Dyes Pigm. 2014, 110, 203-213; i) B. R. Raju, M. M. T. Carvalho, M. I. P. S. Leitão, P. J. G. Coutinho, M. S. T. Gonçalves, Dyes Pigm. 2016, 132, 204-212.

[15] a) S. M. Pauff, S. C. Miller, Org. Lett. 2011, 13, 6196-6199; b) A. Choi, S. C. Miller, Org. Lett. 2018, 20, 4482-4485.

[16] X. Luo, L. Gu, X. H. Qian, Y. C. Yang, Chem. Commun. 2020, 56, 90679078.

[17] Q. Zhang, Z. Zhu, Y. Zheng, J. Cheng, N. Zhang, Y.-T. Long, J. Zheng, X. Qian, Y. Yang, J. Am. Chem. Soc. 2012, 134, 18479-18482.

[18] J. Zhang, X. Chai, X.-P. He, H.-J. Kim, J. Yoon, H. Tian, Chem. Soc. Rev. 2019, 48, 683-722.

[19] a) Y. Yang, S. K. Seidlits, M. M. Adams, V. M. Lynch, C. E. Schmidt, E. V. Anslyn, J. B. Shear, J. Am. Chem. Soc. 2010, 132, 13114-13116; b) Y. Shen, Q. Zhang, X. Qian, Y. Yang, Anal. Chem. 2015, 87, 1274-1280; c) P. R. Escamilla, Y. Shen, Q. Zhang, D. S. Hernandez, C. J. Howard, X. Qian, D. Y. Filonov, A. V. Kinev, J. B. Shear, E. V. Anslyn, Y. Yang, Chem. Sci. 2020, 11, 1394-1403; d) Y. Yu, X. Zhang, Y. Dong, X. Luo, X. Qian, Y. Yang, Sens. Actuators B 2021, 346, 130562.

[20] a) S. Debieu, A. Romieu, Org. Biomol. Chem. 2017, 15, 2575-2584; b) S. Debieu, A. Romieu, Tetrahedron Lett. 2018, 59, 1940-1944; c) K. Renault, S. Debieu, J.-A. Richard, A. Romieu, Org. Biomol. Chem. 2019, 17, 8918-8932.

[21] W. A. Prütz, J. Chem. Soc., Chem. Commun. 1994, 1639-1640.

[22] L. Wang, J. Liu, S. Zhao, H. Zhang, Y. Sun, A. Wei, W. Guo, Chem. Commun. 2020, 56, 7718-7721.

[23] a) Y. Koide, Y. Urano, K. Hanaoka, T. Terai, T. Nagano, ACS Chem. Biol. 2011, 6, 600-608; b) Y. Koide, Y. Urano, K. Hanaoka, W. Piao, M. Kusakabe, N. Saito, T. Terai, T. Okabe, T. Nagano, J. Am. Chem. Soc. 2012, 134, 5029-5031. 
[24] For a comprehensive review, see: L. Wang, W. Du, Z. Hu, K. Uvdal, L. Li, W. Huang, Angew. Chem., Int. Ed. 2019, 58, 14026-14043.

[25] A. V. Anzalone, T. Y. Wang, Z. Chen, V. W. Cornish, Angew. Chem. Int Ed. 2013, 52, 650-654

[26] G. Dejouy, K. Renault, I. E. Valverde, A. Romieu, Dyes Pigm. 2020, 180 , Article 108496

[27] F. Deng, L. Liu, W. Huang, C. Huang, Q. Qiao, Z. Xu, Spectrochim. Acta, Part A 2020, 240, 118466.

[28] G. A. Olah, G. K. Surya Prakash, Q. Wang, X.-y. Li, G. K. Surya Prakash, J. Hu, in Encyclopedia of Reagents for Organic Synthesis, 2004.

[29] a) A. Chevalier, J. Hardouin, P.-Y. Renard, A. Romieu, Org. Lett. 2013 15, 6082-6085; b) A. Chevalier, C. Massif, P.-Y. Renard, A. Romieu, Chem. - Eur. J. 2013, 19, 1686-1699; c) A. Chevalier, C. Mercier, L. Saurel, S. Orenga, P.-Y. Renard, A. Romieu, Chem. Commun. 2013, 49, 8815-8817; d) A. Chevalier, P.-Y. Renard, A. Romieu, Org. Lett. 2014, 16, 3946-3949; e) A. Chevalier, W. Piao, K. Hanaoka, T. Nagano, P.-Y. Renard, A. Romieu, Methods Appl. Fluoresc. 2015, 3, 044004; f) M.-D. Hoang, J.-B. Bodin, F. Savina, V. Steinmetz, J. Bignon, P. Durand, G. Clavier, R. Méallet-Renault, A. Chevalier, RSC Adv. 2021, 11, 3008830092.

[30] R. M. DeBaun, G. de Stevens, Arch. Biochemi. Biophys. 1951, 31, $300-$ 308.

[31] E. Howard, W. F. Olszewski, J. Am. Chem. Soc. 1959, 81, 1483-1484.

[32] K. Rurack, M. Spieles, Anal. Chem. 2011, 83, 1232-1242.

[33] A. M. Brouwer, Pure Appl. Chem. 2011, 83, 2213-2228.

[34] C. Bueno, M. L. Villegas, S. G. Bertolotti, C. M. Previtali, M. G. Neumann, M. V. Encinas, Photochem. Photobiol. 2002, 76, 385-390.

[35] For a selected review, see: A. K. Vidanapathirana, P. J. Psaltis, C. A Bursill, A. D. Abell, S. J. Nicholls, Med. Res. Rev. 2021, 41, 435-463.

[36] a) N. Kumar, V. Bhalla, M. Kumar, Coord. Chem. Rev. 2013, 257, 2335 2347; b) H. Li, A. Wan, Analyst 2015, 140, 7129-7141; c) Y. Chen, Nitric Oxide 2020, 98, 1-19; d) L. Wang, J. Zhang, X. An, H. Duan, Org. Biomol. Chem. 2020, 18, 1522-1549.

[37] a) K.-J. Huang, H. Wang, M. Ma, X. Zhang, H.-S. Zhang, Nitric Oxide 2007, 16, 36-43; b) R. Barbosa, A. Lopes, R. Santos, C. Pereira, C Lourenço, B. Rocha, N. R. Ferreira, A. Ledo, J. Laranjinha, Global J. Anal. Chem. 2011, 2, 272-284.

[38] R. Tanikaga, Bull. Chem. Soc. Jpn 1968, 41, 1664-1668.

[39] a) T. M. Kitson, Bioorg. Chem. 1998, 26, 63-73; b) T. M. Kitson, K. E. Kitson, G. J. King, in Adv. Exp. Med. Biol., Vol. 463 (Eds.: H. Weiner, E. MAser, D. W. Crabb, R. Lindahl), Springer, New York, 1999, pp. 89-96.

[40] For a comprehensive review on cysteine-mediated redox signaling, see: C. E. Paulsen, K. S. Carroll, Chem. Rev. 2013, 113, 4633-4679.

[41] a) Y.-Q. Sun, J. Liu, H. Zhang, Y. Huo, X. Lv, Y. Shi, W. Guo, J. Am. Chem. Soc. 2014, 136, 12520-12523; b) X.-X. Chen, L.-Y. Niu, N. Shao, Q.-Z. Yang, Anal. Chem. 2019, 91, 4301-4306.

[42] N. Vijay, S. P. Wu, S. Velmathi, ACS Appl. Bio Mater. 2021, 4, 70077015.

[43] A. Gorman, J. Killoran, C. O'Shea, T. Kenna, W. M. Gallagher, D. F. O'Shea, J. Am. Chem. Soc. 2004, 126, 10619-10631.

[44] G. R. Fulmer, A. J. M. Miller, N. H. Sherden, H. E. Gottlieb, A. Nudelman, B. M. Stoltz, J. E. Bercaw, K. I. Goldberg, Organometallics 2010, 29 2176-2179. 
<smiles>CCNc1ccc2nc3ccc(=[N+](CC)CC)cc-3oc2c1</smiles>

Oxazine 1 (0x-1)<smiles>CCN(CC)c1ccc2nc3c4ccccc4c(=O)cc-3oc2c1</smiles>

HO<smiles>Cc1ccc2nc3ccc(=O)cc-3oc2c1</smiles>

Resorufin (RF)<smiles>O=c1ccc2[n+]([O-])c3ccc(O)cc3oc-2c1</smiles>

Resazurin (RZ)

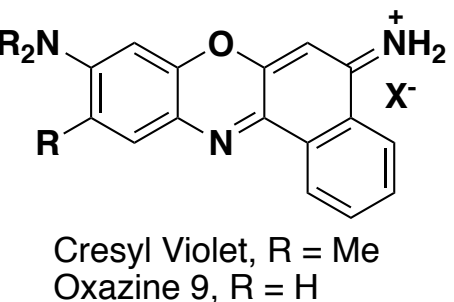

Nile Blue

Figure 1. Structures of the most popular phenoxazine dyes currently used in fluorescence-based applications $\left(\mathrm{X}^{-}=\mathrm{Cl}^{-}\right.$or $\left.\mathrm{ClO}_{4}^{-}\right)$. 
<smiles>CCN(CC)c1cccc(Oc2cc(N(CC)CC)ccc2N)c1</smiles><smiles>[GeH3]OCO[GeH3]</smiles><smiles></smiles>

$0 x-1$
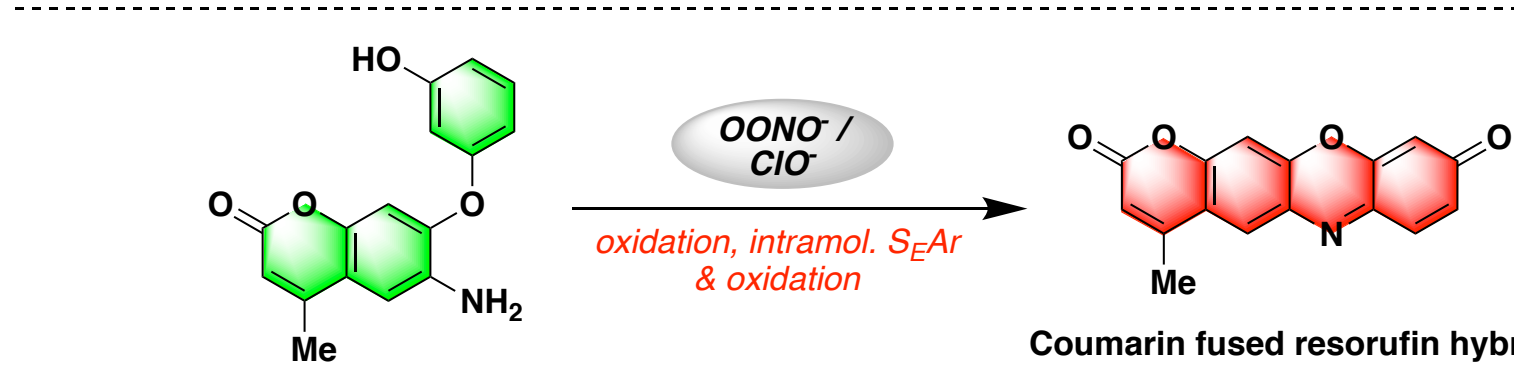

PN600

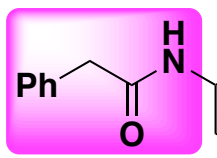

PGA-sensitive trigger<smiles>CC(=O)C=C(Oc1ccccc1NC(=O)Cc1ccccc1)C(C)=O</smiles>

\section{Coumarin fused resorufin hybrid}

Dual-reactable probe 1

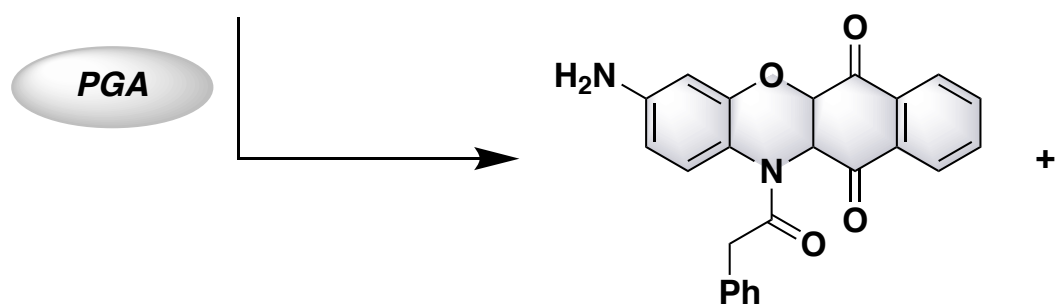

2<smiles>Nc1ccc2c(c1)OC1C(=O)c3ccccc3C3=C(c4ccccc4)C(=O)N3C21</smiles>

3

Figure 2. Overview of "covalent-assembly" fluorescent probes reported in the literature, whose activation leads to the in situ formation of phenoxazine dyes or related analogs $\left[\mathrm{ClO}^{-}=\right.$hypochlorite anion, $\mathrm{OONO}^{-}=$peroxynitrite anion, $\mathrm{PGA}=$ penicillin $\mathrm{G}$ acylase, $\mathrm{PhAc}=$ phenylacetyl, $\mathrm{X}^{-}=$counter ion not specified]. ${ }^{\text {a Please note: }}$ the proneness of probe $\mathbf{N O 6 7 0}$ to auto-oxidation mitigated its potential for practical applications. Synthesis of $\mathbf{N O 6 7 0}$ and mechanistic studies related to its conversion into Ox-1 were not published by the Yang group but only mentioned in their review on the "covalent-assembly" principle for fluorescent probe design ${ }^{[16]}$. 
<smiles>[R]N([R])c1cccc(Oc2cccc(N([R])[R])c2)c1</smiles>

Bis(3-dialkylaminophenyl) ether

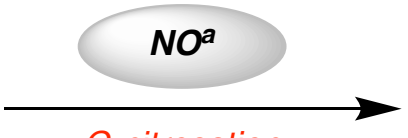

C-nitrosation<smiles>[R]N([R])c1ccc2c(c1)Oc1cc([N+](=O)[O-])ccc1N(C)CC2</smiles><smiles>Cn1ccc(OC(=O)O)c1</smiles><smiles></smiles>
$\mathrm{H}^{+}$abstraction $^{b}$<smiles>[R]N([R])c1ccc2nc3ccc(=[N+]([X])[R])cc-3oc2c1</smiles>

Phenoxazine

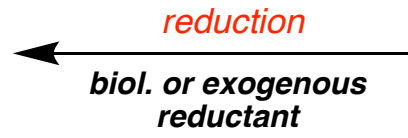
reductant<smiles>[R]N([R])c1ccc2c(c1)oc1cc(=[N+]([R])P)ccc-1[n+]2[O-]</smiles>

$\mathrm{N}$-oxide derivative

Figure 3. NO-sensing strategy explored in this work based on the use of "covalent-assembly" fluorogenic probes whose activation leads to the in situ formation of phenoxazine dyes [biol. = biological, $\mathrm{Nu}=$ nucleophilic, $\mathrm{R}=$ alkyl substituent, $\mathrm{X}^{-}=$counter ion not specified]. ${ }^{\text {aPlease note: }}$ depending the context, the nitrosating species is different: $\mathrm{NO}^{+}$in the case of syntheses using $\mathrm{NOBF}_{4}$ and probably $\mathrm{N}_{2} \mathrm{O}_{3}$ (itself in equilibrium with $\mathrm{NO}^{+}$and $\mathrm{NO}_{2}^{-}$) in the case of experiments performed with freshly prepared aq. solution of nitric oxide. ${ }^{b}$ Please note: depending the context, proton abstraction may be assisted by various species: $\mathrm{BF}_{4}^{-}$anion, $\mathrm{H}_{2} \mathrm{O}$ molecule, $\mathrm{NO}_{2}{ }^{-}$ anion or $\mathrm{N}$-oxide derivative itself. 
$\mathrm{Br}$<smiles></smiles>

$\mathrm{Me}_{2} \mathrm{~N}{ }_{\mathrm{OH}}^{\mathrm{OH}}$

3-(dimethylamino) phenol 3-bromo-

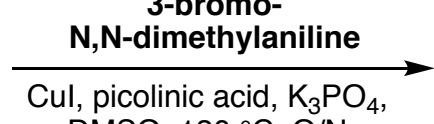
DMSO, $130^{\circ} \mathrm{C}, \mathrm{O} / \mathrm{N}$

$75 \%$
$\mathrm{Me}_{2} \mathrm{~N}$<smiles>CN(C)c1cccc(Oc2cccc(I)c2)c1</smiles>

4

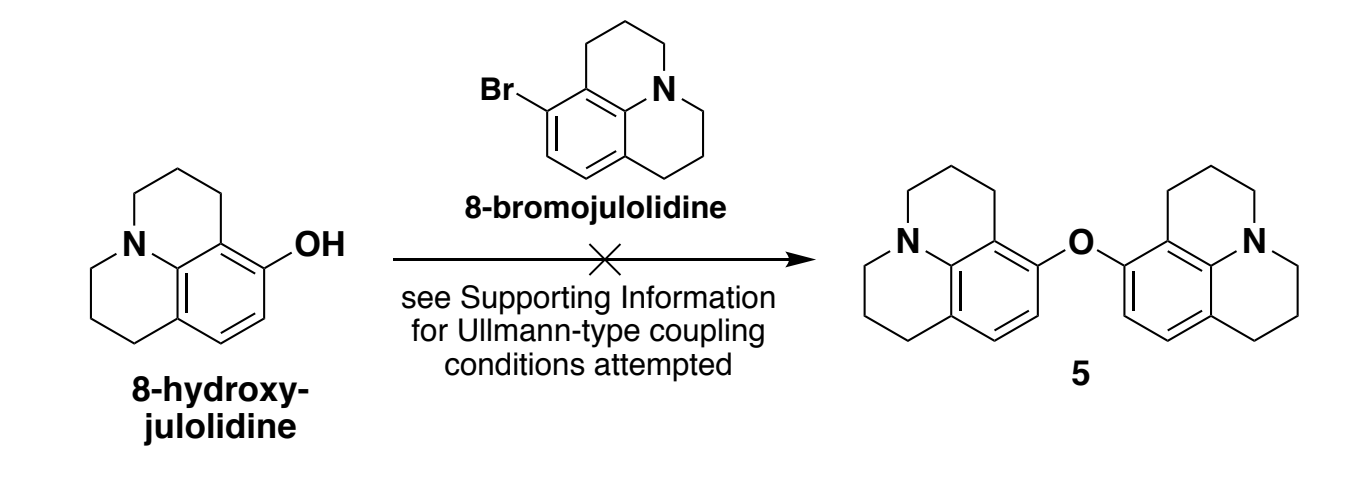<smiles>CN(C)c1cccc(Br)c1</smiles>

3-bromo-

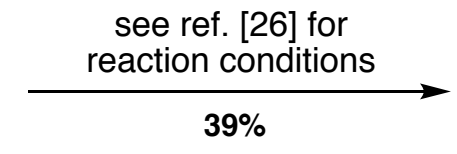

$39 \%$

\section{$\mathrm{N}, \mathrm{N}$-dimethylaniline}<smiles>CN(C)c1cccc([Si](C)(C)c2cccc(N(C)C)c2)c1</smiles>

DAEA-Si 6

Scheme 1. Synthesis of symmetrical bis-aryl ethers 4 and 5 and the silicon-containing analog DAEA-Si $\mathbf{6}$. [O/N = overnight]. 


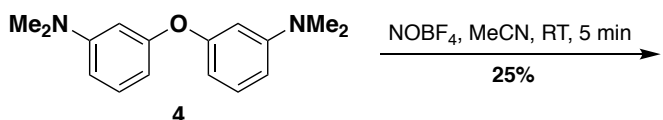

4

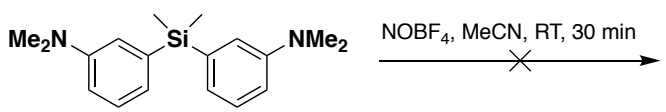

DAEA-Si 6

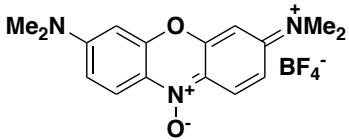

7 (tetrafluoroborate salt)

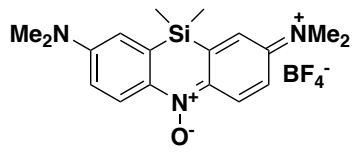

9 (tetrafluoroborate salt)

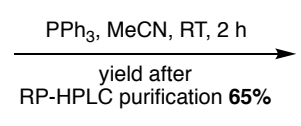

RP-HPLC purification $65 \%$

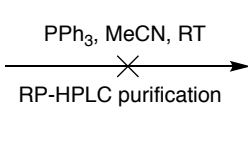

RP-HPLC purification

$\mathrm{Me}_{2} \mathrm{~N}$

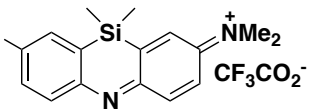

10 (trifluoroacetate salt)

Scheme 2. Synthesis of phenoxazine dye 8 and its silicon analog 10 through $\mathrm{NOBF}_{4}$-mediated nitrosation. [RT = room temperature]. 

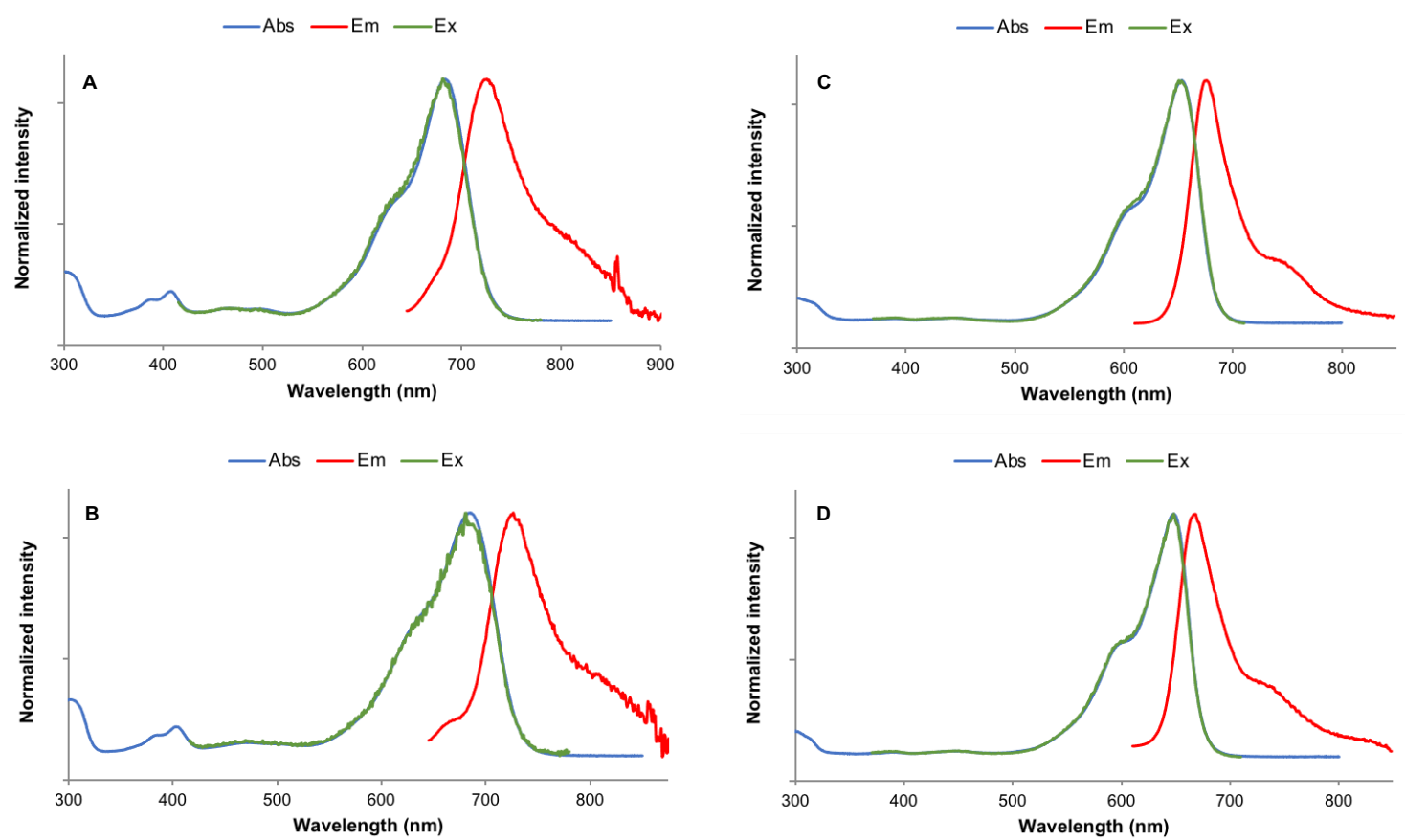

Figure 4. Normalized absorption, fluorescence emission (excitation at $630 \mathrm{~nm}$ (A-B) or $600 \mathrm{~nm}$ (C-D), Ex/Em slits $5 \mathrm{~nm}$ ) and excitation (emission at $800 \mathrm{~nm}(\mathrm{~A}-\mathrm{B})$ or $720 \mathrm{~nm}(\mathrm{C}-\mathrm{D})$, Ex/Em slits $5 \mathrm{~nm}$ ) spectra of phenoxazine dyes 7 and 8 in DMSO (A, C), and in ultrapure water $(B, D)$ at $25^{\circ} \mathrm{C}$. 

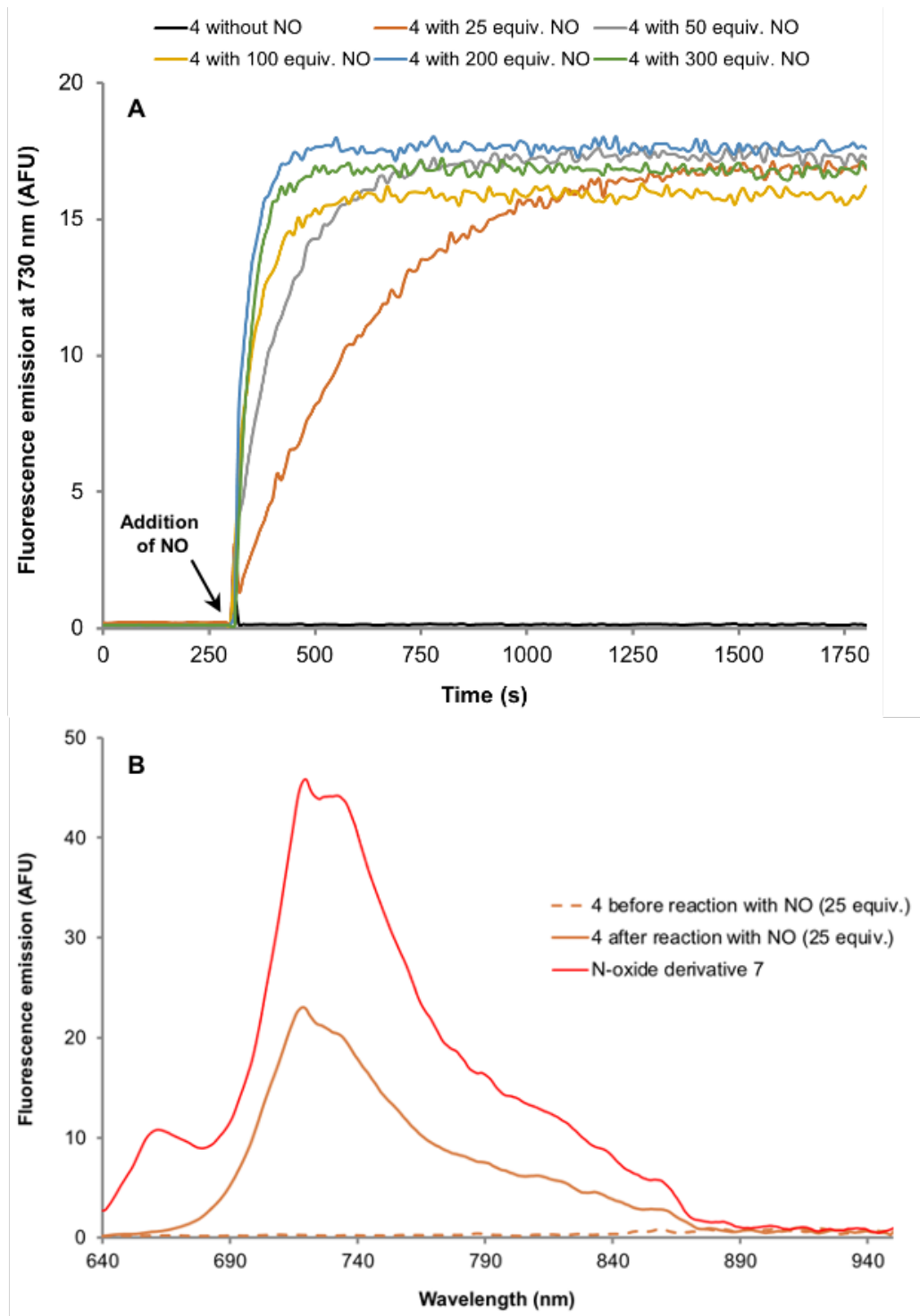

Figure 5. (A) Fluorescence emission time course (Ex/Em $685 / 730 \mathrm{~nm}$, bandwidth $5 \mathrm{~nm}$, PMT voltage $600 \mathrm{~V}$ ) of "covalent-assembly" fluorogenic probe 4, concentration: $10 \mu \mathrm{M}$, in the presence of various amounts of $\mathrm{NO}$, in ultrapure water at $25^{\circ} \mathrm{C}$. (B) Overlay of fluorescence emission spectra (Ex at $630 \mathrm{~nm}$, bandwidth $5 \mathrm{~nm}$, PMT voltage $600 \mathrm{~V}$ ) of "covalent-assembly" fluorogenic probe 4 before and after $25 \mathrm{~min}$ incubation with NO (25 equiv.), and N-oxide derivative 7 (reference sample synthesized from 4 with NOBF 4 , see Scheme 2) at the same concentration $(10 \mu \mathrm{M})$ in ultrapure water at $25^{\circ} \mathrm{C}$. Please note: the presented kinetics and emission curves were recorded with a SAFAS FIX-Xenius XC spectrofluorimeter, an instrument that is well suited for high-throughput measurements (e.g., 10 different kinetics at the same time) but providing lower performances than HORIBA Jobin Yvon Fluorolog in the NIR-I spectral range; this explains the poorer quality of emission spectra compared to those presented in Figure 4 . The minor band centered at 660 $\mathrm{nm}$ and observed in the emission spectrum of reference sample of $\mathbf{7}$, is assigned to phenoxazine $\mathbf{8}$, formed through a not yet elucidated (photo)reduction process occurring during the prolonged storage of 7 in solution (i.e., $1.0 \mathrm{mg} / \mathrm{mL}$ stock solution in DMSO). 

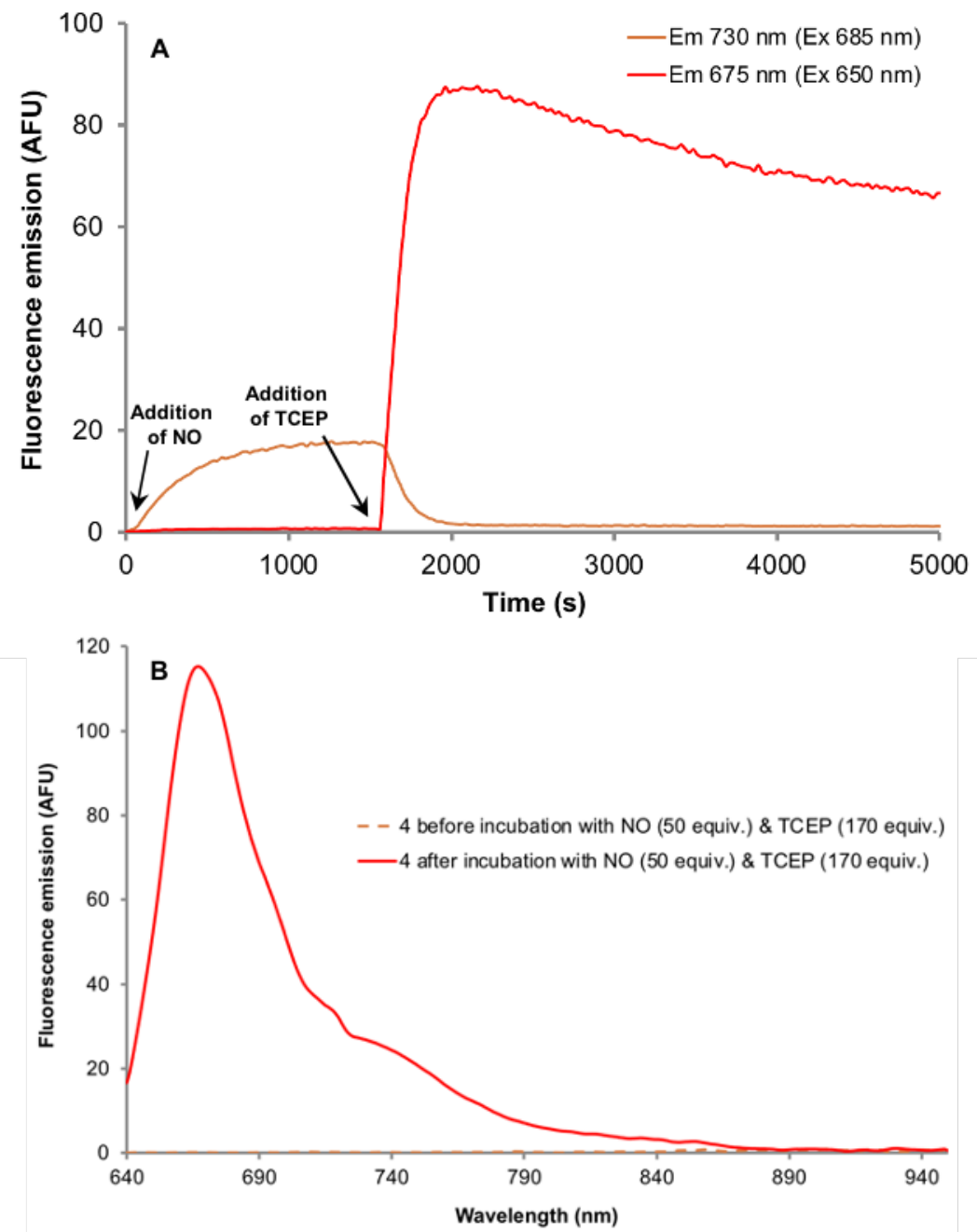

Figure 6. (A) Fluorescence emission time course (channel 1: Ex/Em 685/730 nm for 7, channel 2: Ex/Em 650/675 nm for 8; bandwidth $5 \mathrm{~nm}$, PMT voltage $600 \mathrm{~V}$ ) of "covalent-assembly" fluorogenic probe 4, concentration: $10 \mu \mathrm{M}$, sequentially incubated with NO (50 equiv.) and TCEP (170 equiv.), in ultrapure water at $25^{\circ} \mathrm{C}$. (B) Fluorescence emission spectra (Ex at $630 \mathrm{~nm}$, bandwidth $5 \mathrm{~nm}$, PMT voltage $600 \mathrm{~V}$ ) of "covalent-assembly" fluorogenic probe 4, concentration: $10 \mu \mathrm{M}$, before and after sequential incubation with NO (50 equiv.) and TCEP (170 equiv.), in ultrapure water at $25^{\circ} \mathrm{C}$. 

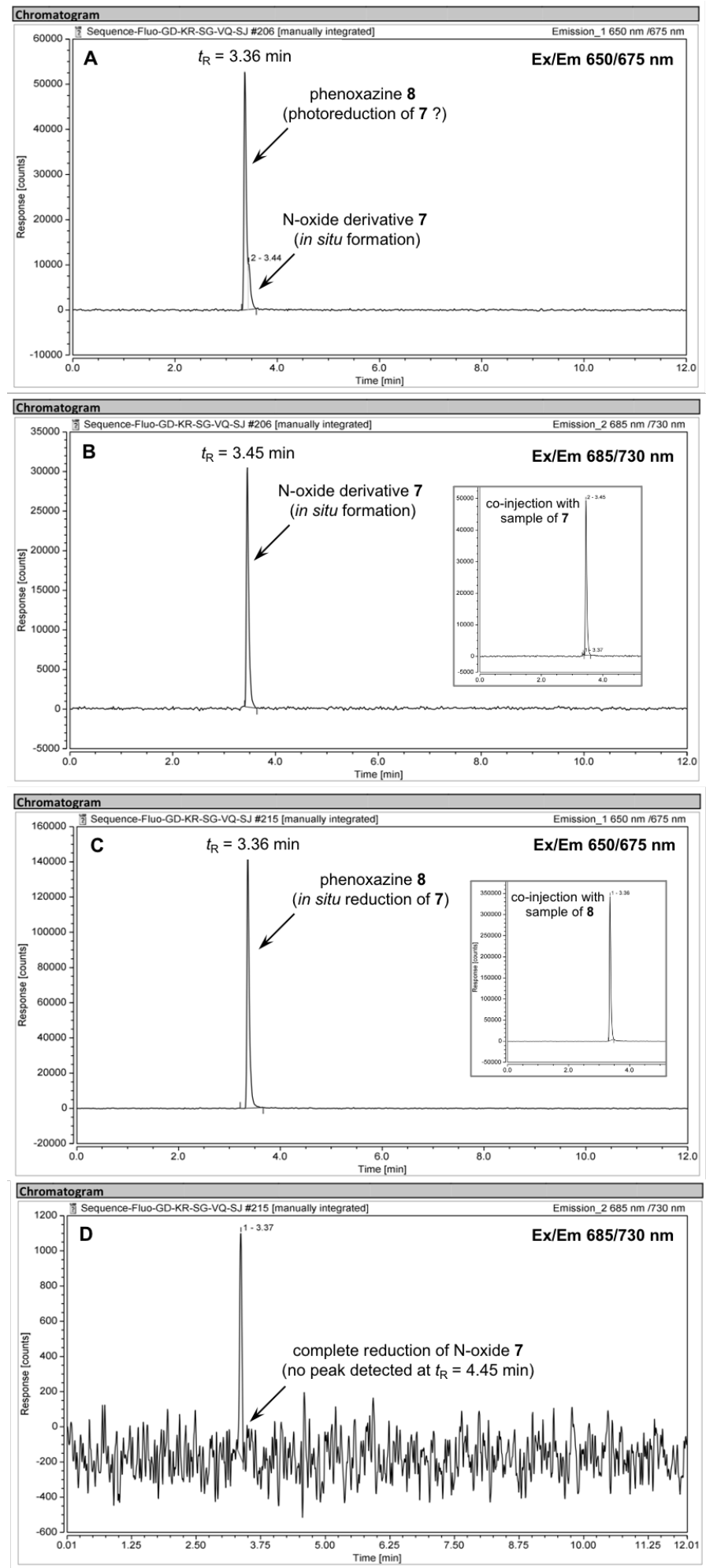

Figure 7. RP-HPLC elution profiles (system C, fluorescence detection in two distinct channels: Ex/Em 650/675 nm and Ex/Em 685/730 $\mathrm{nm}$ ) of reaction mixtures of "covalent-assembly" fluorogenic probe 4 with NO (50 equiv.) for 25 min at $25^{\circ} \mathrm{C}$ (A-B), or with NO (50 equiv., 25 min of incubation) and TCEP (170 equiv., 60 min of incubation) at $25^{\circ} \mathrm{C}(C-D)$. Please note: see inset of (B) and (C) for coinjection analysis of the corresponding reaction mixture with an authentic sample of 7 or 8 . 

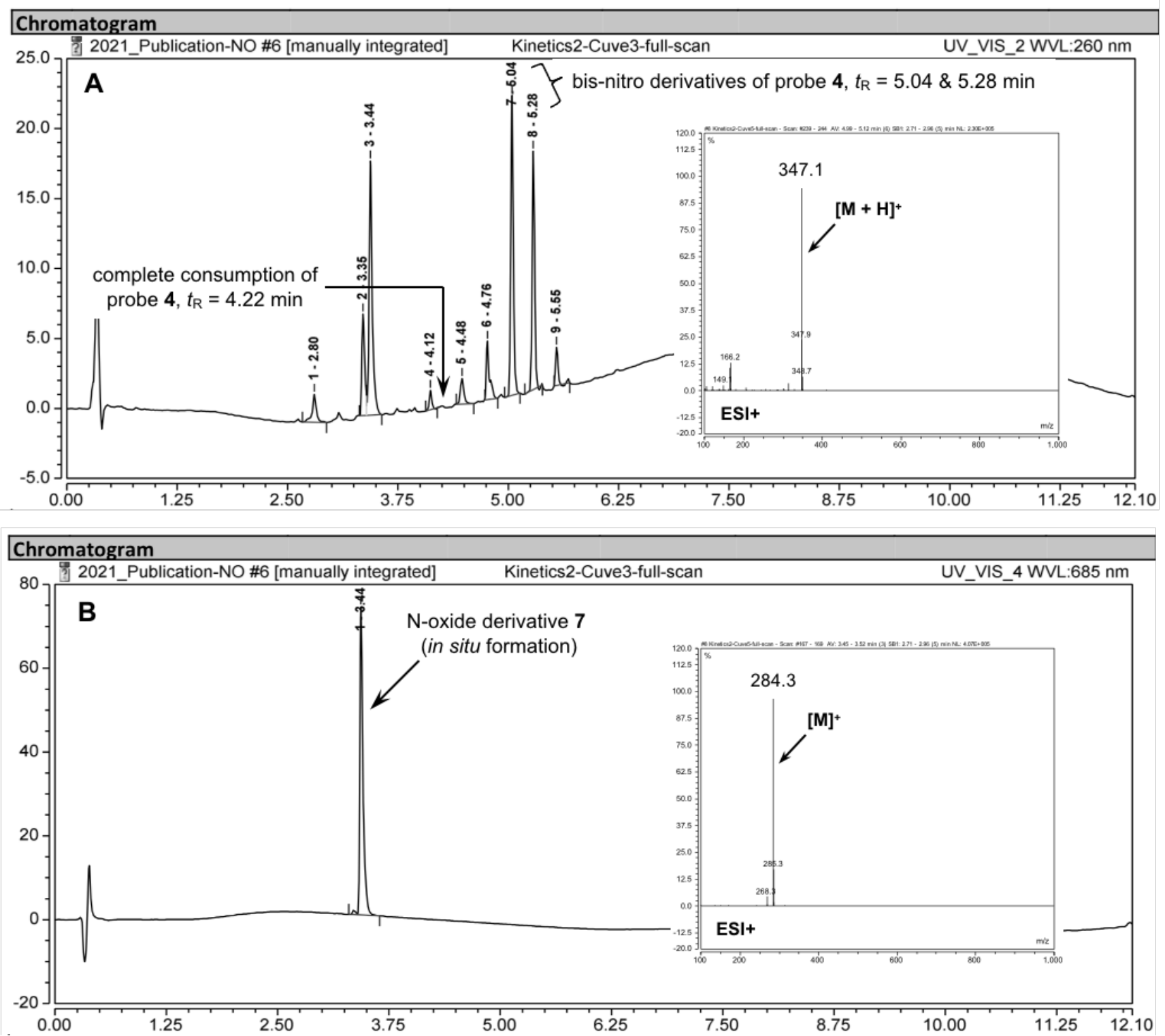

Figure 8. RP-HPLC elution profiles (system D) of "covalent-assembly" fluorogenic probe 4 after 25 min incubation with NO (50 equiv.) in ultrapure water at $25^{\circ} \mathrm{C}$. (A) UV detection at $260 \mathrm{~nm}$ and ESI+ mass spectrum of peaks at $t_{\mathrm{R}}=5.04$ and 5.28 min (inset). (B) Visible detection at $685 \mathrm{~nm}$ and $\mathrm{ESI}+$ mass spectrum of peak at $t_{\mathrm{R}}=3.44$ min (inset). 

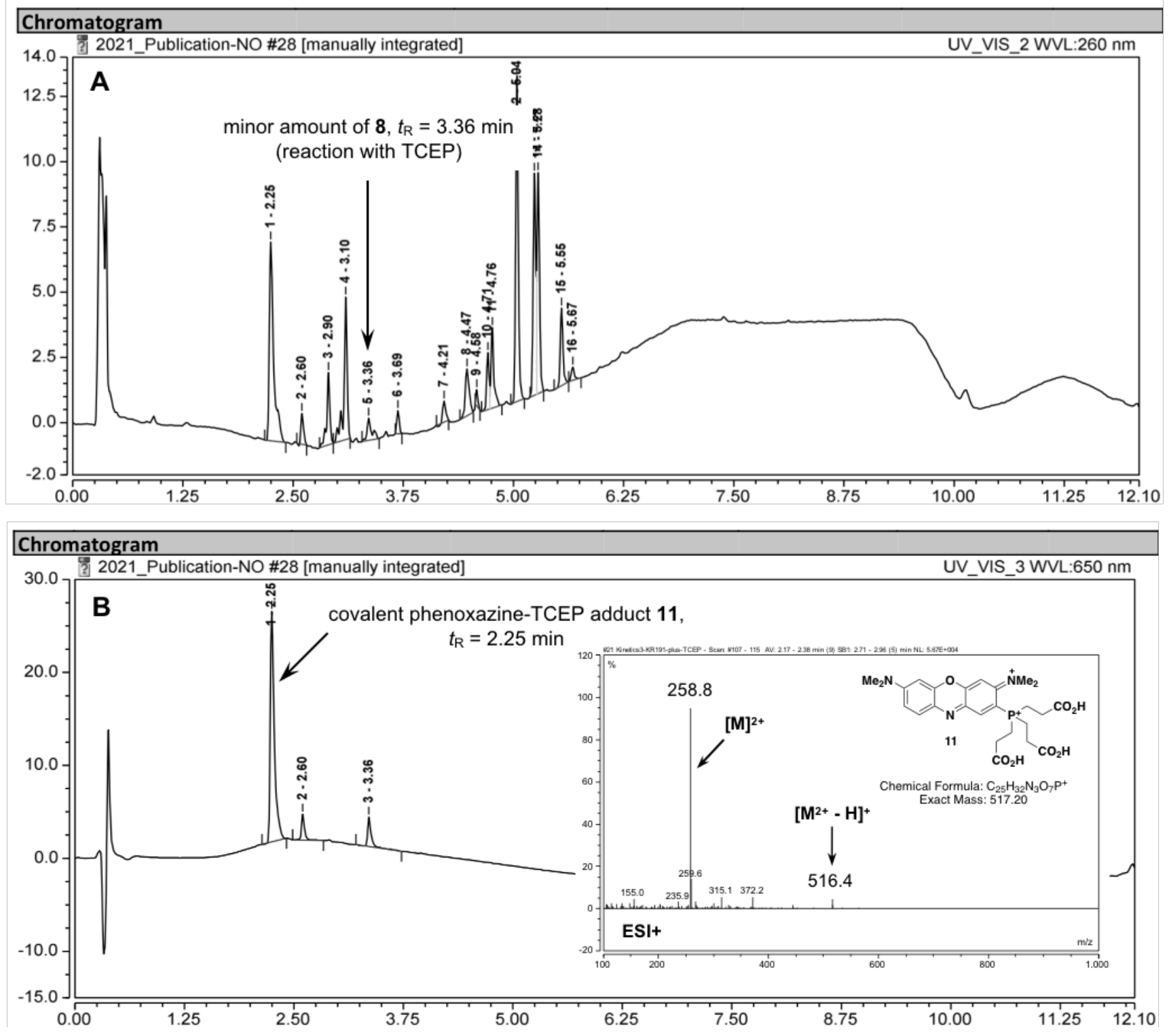

Figure 9. RP-HPLC elution profiles (system D) of "covalent-assembly" fluorogenic probe 4 after sequential incubation with NO (50 equiv., 25 min of incubation) and TCEP (170 equiv., $60 \mathrm{~min}$ of incubation) in ultrapure water, at $25^{\circ} \mathrm{C}$. (A) UV detection at $260 \mathrm{~nm}$. (B) Visible detection at $650 \mathrm{~nm}$ and $\mathrm{ESI}+$ mass spectrum of peak at $t_{\mathrm{R}}=2.25 \mathrm{~min}$ (inset). 


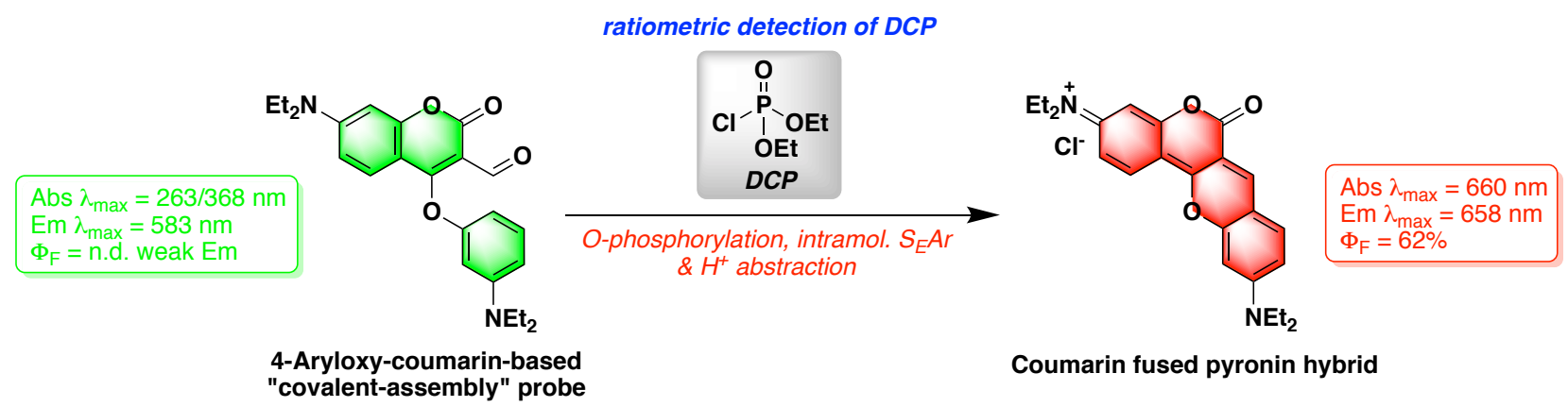

Figure 10. "Covalent-assembly" fluorescent probe recently reported by Vijay et al. ${ }^{[42]}$ for ratiometric detection of nerve-agent mimic DCP [diethyl chlorophosphate] within the NIR-I spectral range. Please note: spectral features of probe and in situ formed coumarin fused pyronin hybrid dye were determined in DMSO. 


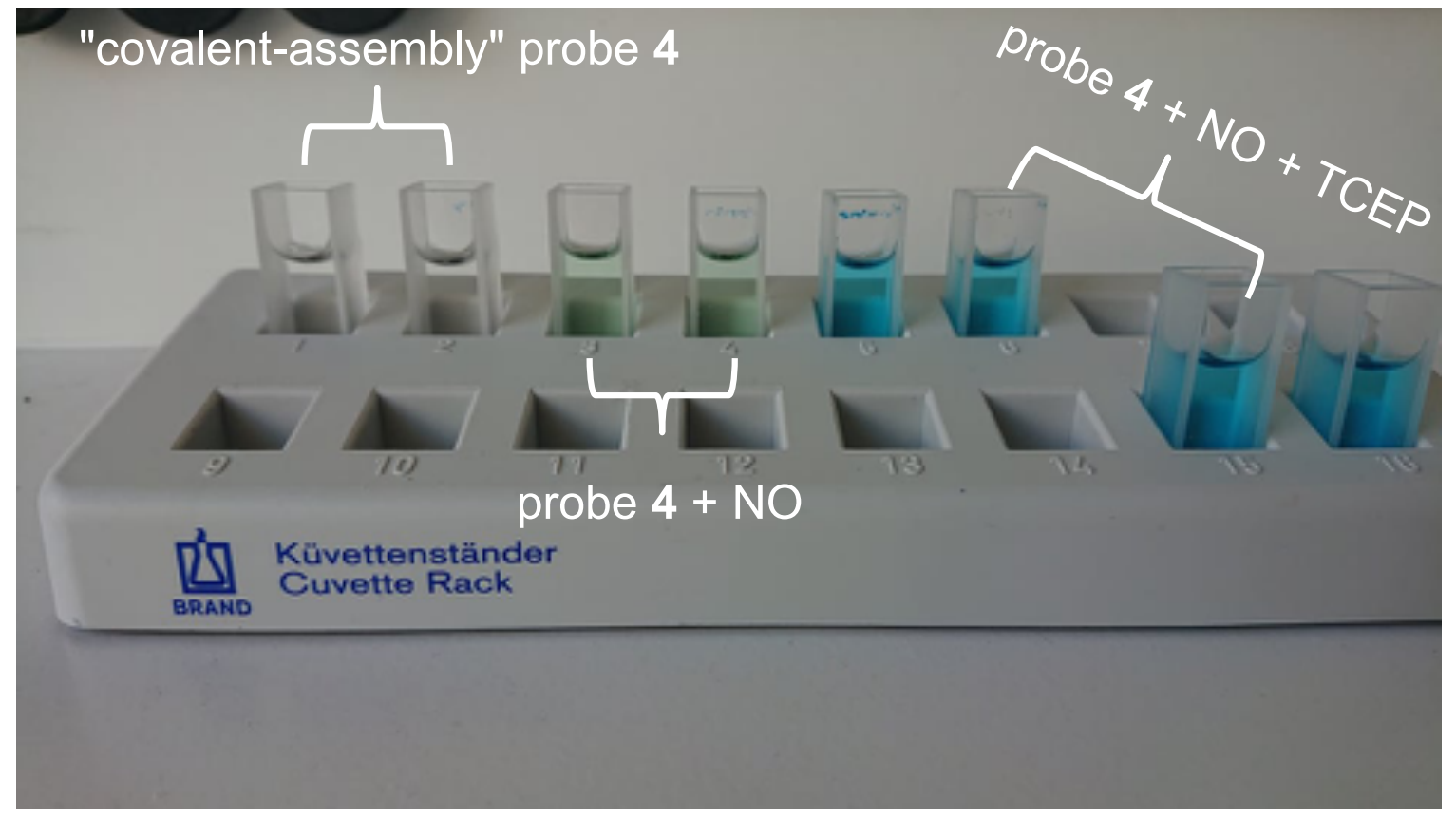

Figure S1. Picture of aq. solutions of "covalent-assembly" fluorogenic probe 4 before and after incubation with either NO (50 equiv.) or NO (50 equiv.) and TCEP (170 equiv.). 